BNL- 52469

FORMAL

\title{
Overview of Research and Development in Subsurface Fate and Transport Modeling
}

Terrence M. Sullivan Brookhaven National Laboratory Associated Universities, Inc.

and

Mondher Chehata

Science Applications International Corporation

May 1995 
2 


\section{ACKNOWLEDGEMENT}

This research was supported by the Plumes Focus Area, Office of Technology Development, Office of Environmental Management, United States Department of Energy, under contracts DE-AC02-76CH00016 and DE-AC01-93EW50512.

The authors would like to acknowledge the support of Jeffrey Walker, Leader of the Plumes Focus Area, and the comments and suggestions provided by the peer reviewers Drs. F. J. Wobber, DOE/OER Subsurface Science Program; P. K. M. van der Heijde, International Ground Water Modeling Center; J. Holland, Waterways Experiment Station, U.S. Army Corps of Engineers; J. O. Rumbaugh III, Geraghty \& Miller Inc.; J. L. Yow, Jr., Lawrence Livermore National Laboratory; and J. Hailer, Waste Policy Institute.

The authors would like to thank leaders of various programs cited in this report for providing the best available information concerning fate and transport modeling research and development under various initiatives sponsored by government agencies. They also would like to thank Carolee Davis and Yolonda Christy, from SAIC, and Grace Webster, from BNL, for editing and preparing the final document.

\section{DISCLAIMER}

This report was prepared as an account of work sponsored by an agency of the United States Government. Neither the United States Government nor any agency thereof, nor any of their employees, makes any warranty, express or implied, or assumes any legal liability or responsibility for the accuracy, completeness, or usefulness of any information, apparatus, product, or process disclosed, or represents that its use would not infringe privately owned rights. Reference herein to any specific commercial product, process, or service by trade name, trademark, manufacturer, or otherwise does not necessarily constitute or imply its endorsement, recommendation, or favoring by the United States Government or any agency thereof. The views and opinions of authors expressed herein do not necessarily state or reflect those of the United States Government or any agency thereof. 


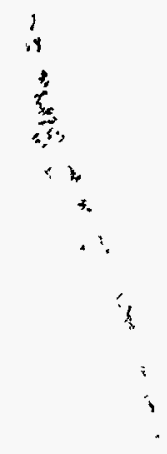




\section{DISCLAIMER}

Portions of this document may be illegible in electronic image products. Images are produced from the best available original document. 


\section{EXECUTIVE SUMMARY}

The U.S. Department of Energy is responsible for the remediation of over 450 different subsurface-contaminated sites. Contaminant plumes at these sites range in volume from several to millions of cubic yards. The concentration of contaminants also ranges over several orders of magnitude. Contaminants include hazardous wastes such as heavy metals and organic chemicals, radioactive waste including tritium, uranium, and thorium, and mixed waste, which is a combination of hazardous and radioactive wastes. The physical form of the contaminants includes solutes, nonaqueous phase liquids (NAPLs), and vapor phase contaminants such as volatilized organic chemicals and radon.

The subject of contaminant fate and transport modeling is multi-disciplinary, involving hydrology, geology, microbiology, chemistry, applied mathematics, computer science, and other areas of expertise. It is an issue of great significance in the United States and around the world. As such, many organizations have substantial programs in this area. In gathering data to prepare this report, a survey was performed of research and development work that is funded by U.S. government agencies to improve the understanding and mechanistic modeling of processes that control contaminant movement through subsurface systems. Government agencies which fund programs that contain fate and transport modeling components include the Environmental Protection Agency, Nuclear Regulatory Commission, Department of Agriculture, Department of Energy, National Science Foundation, Department of Defense, United States Geological Survey, and National Institutes of Health.

This report reaffirms the importance of contaminant fate and transport modeling in all areas of environmental management. Models, which are tools used to gain an understanding of a system's response to stresses and physical processes, are essential and highly valuable for site characterization and assessment, remedial investigations and feasibility studies, environmental assessments, remedial designs, performance assessments, and other aspects of environmental restoration and waste management.

Despite the benefits of currently available contaminant fate and transport models, several weaknesses and misapplications have been identified in existing practices. Several subsurface fate and transport processes are still poorly understood and improperly assessed. However, great pressure is often placed on users to come up with definitive answers using whatever tools are available to them, even if the tools are not applicable or introduce unacceptable limitations. Improper model application, unfortunately, occurs much too often in attempting to solve the various problems encountered in environmental restoration and waste management. Decisions are made using incomplete or incorrect data that proved to be inadequate once implemented, 
various problems encountered in environmental restoration and waste management. Decisions are made using incomplete or incorrect data that proved to be inadequate once implemented, and often lead to unnecessarily high costs of remediation. Risk related to contaminant transport is frequently overestimated to compensate for unknowns, and complex naturally occurring geochemical and biological attenuation is not properly represented. A continuing effort must be made to educate regulators, decision-makers, and the public about the benefits and cost savings that can be achieved by developing and using appropriate rather than available models, and from adequately selecting and training the personnel involved in environmental modeling.

In the present review, which was completed in December 1994, over 150 Federally supported modeling initiatives were identified. They placed major emphasis on decision support systems, groundwater management, multi-phase multi-component transport, solute transport, and stochastic modeling. Less but still significant emphasis was placed on model improvements in biodegradation and bioremediation, fracture flow, multi-component solute transport, microbial transport, pesticide transport, improved numerical solution techniques, optimal design, and data collection and management. Based on the findings, specific areas have been identified for which improvements will help the development and proper use of models. The following general areas need additional emphasis and support:

a) Process Understanding and Modeling

- Coupled geochemical multi-species, multi-component fate and transport

- $\quad$ Coupled microbial transport

- Impact of heterogeneities on flow and transport

- Non-isothermal multi-phase flow and transport (NAPL remediation)

- Influence of remediation efforts on fate and transport (performance assessment)

- $\quad$ Fracture flow

- $\quad$ Stochastic modeling

b) Numerical Modeling

- Parallel processing algorithms

- $\quad$ Efficient discretization techniques (adaptive mesh refinement)

- $\quad$ Advanced numerical solution techniques (matrix solution, numerical integration)

- Alternative approaches to mathematical modeling (neural networks)

c) Information Processing

- Visualization techniques for input and output processing 
- Data reduction (data fusion)

- Geostatistical mapping

- $\quad$ Data standardization to simplify transfer between different hardware and software platforms

- Geographic information systems applications

d) Coordination of Model Research, Development and Application

- $\quad$ Minimization of duplication of effort

- Integration of knowledge between different programs

- Guidance on model acceptability

- $\quad$ Guidance on model verification and confidence-building

- Coordination of training and technical transfer of models

Improvements in process modeling will provide better tools to address the complex issues related to subsurface fate and transport. This will allow better decisions to be made concerning remediation issues. Chemical contamination with mixtures of contaminants has been shown to be a widespread problem. More attention is needed to increase understanding of the impact of chemical and biological reactions on transport. These effects are poorly understood in many natural systems and can greatly affect long-term estimates of transport. Model development programs will need to interact with experimental programs and should be focused on addressing the most common and important problems.

In addition, improved process models are needed to assist in obtaining better estimates of the fate and transport of NAPLs, the effect of heterogeneities on transport, and the role of fractures on flow and transport. An accurate analysis of fate and transport modeling in each of these areas is not always possible at this time. Several specific issues require additional R\&D work. These include NAPL blob formation and transport, heterogeneities in transport parameters and chemical reactivity, and large-scale fracture flow, and transport. In each of these areas, model development in the absence of experimental data will most likely be unsuccessful. Substantial experimental work will be needed in conjunction with model development.

As models become more complex and require increased computational sophistication, improved numerical techniques and innovative problem-solving approaches will be necessary. They will assist in problems with large amounts of data, large computational problem size, and large modeled domains where changes occur rapidly over localized regions.

Improved information processing will reduce model implementation error and facilitate the proper use of models. This will include improved input/output interfaces for computer models, such as input processing techniques that assist in 
specifying the geometry and heterogeneity in the subsurface system. Better information processing will take all the data used to characterize a site and incorporate it into the system conceptual model. Improved data visualization techniques are needed to assist in the interpretation of model predictions. Several data visualization techniques are currently available, but they are not integrated with fate and transport models.

Focused coordination of model development and application is the area in which immediate action will improve use of existing models and focus development on model improvements. Modeling of subsurface systems requires expertise in a wide range of disciplines including geology, hydrology, biochemistry, microbiology, numerical analysis, and geology statistics. Each discipline has a limited perspective of the overall objective. Therefore, oversight will help integrate the different disciplines, set priorities, and effectively facilitate the transfer of technology to the users and enhance proper application of models.

Coordination will help ensure that an integrated approach is used that accounts for user needs. Development and use of decision support systems can effectively enhance the probability of incorporating all facets of the problem into the decision-making process. Where existing process models are inadequate, efforts should be made to address model inadequacies. In this case, coordination will help prioritize the needs for model development.

To encourage proper use of models, technical transfer should be supplied through more thorough training. Model applications are focused on providing the decision-maker with additional information to support the decision, including meeting regulatory limits, assessing the extent of contamination, and selecting remedial alternatives. Often, the decision-makers are not well versed in the intricacies of subsurface fate and transport modeling. Training decision-makers, contractors involved in modeling, and other stakeholders will improve the implementation and interpretation of models and their end product.

The ultimate concern about contaminant disposal is the way that contaminants will affect human health and the environment. Subsurface fate and transport modeling, in conjunction with site characterization and data collection, will play a central role in assessing the risks of disposal and the outcomes of remediation alternatives. Indeed, risk assessment and pathway analysis models use predictions from fate and transport models as input to evaluate impacts on human health and the environment. To this end, risk assessment and environmental impact analyses of contaminated soils and groundwater rely on model estimations of mass fluxes and contaminant concentration distributions in the various receptor media. The importance of fate and transport models in assessing risk highlights the need for development of improved models. 
Finally, it is crucial that managers and decision makers understand the benefits provided by environmental models and change the myth that modeling is a money sink. It is long overdue to recognize that investing in modeling research and development, as well as training of specialized modelers represents a very small fraction of potential cost savings that can be generated through the application of appropriate modeling tools in future environmental management efforts. In addition, contaminant fate and transport modeling is a main concern for several Federal agencies. More effective coordination and cooperation between these different agencies will help minimize duplication of effort, help leverage programs such that common areas of interest can be addressed more effectively, and promote the dissemination of experience and knowledge between different groups. 


\section{TABLE OF CONTENTS}

ACKNOWLEDGEMENT $\ldots \ldots \ldots \ldots \ldots \ldots \ldots$ iii

EXECUTIVE SUMMARY $\ldots \ldots \ldots \ldots \ldots \ldots \ldots \ldots$ v

LIST OF TABLES $\ldots \ldots \ldots \ldots \ldots \ldots \ldots \ldots \ldots \ldots \ldots \ldots$

ACRONYMS AND ABBREVIATIONS $\ldots \ldots \ldots \ldots \ldots \ldots$ xvii

1. INTRODUCTION $\ldots \ldots \ldots \ldots \ldots \ldots \ldots \ldots \ldots \ldots$

2. SUBSURFACE CONTAMINANT TRANSPORT: PROBLEM

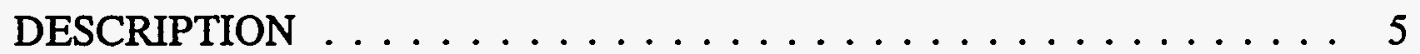

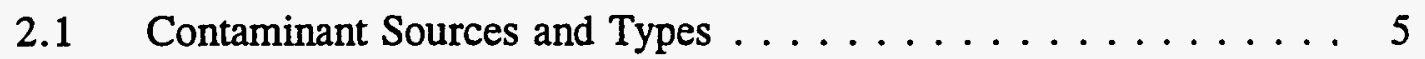

2.1.1 Technical Approach for Waste Classification . . . . . . 6

2.1.2 Results of Waste Classification . . . . . . . . . 6

2.1.3 Special Considerations for Fate and Transport Modeling . . . 8

2.2 Fluid Flow Processes $\ldots \ldots \ldots \ldots \ldots \ldots \ldots$

2.3 Transport Processes $\ldots \ldots \ldots \ldots \ldots \ldots \ldots \ldots \ldots$

2.4 Role of Remediation in Altering Flow and Transport . . . . . . 14

2.5 Connection with Risk Assessment Models . . . . . . . . . . 14

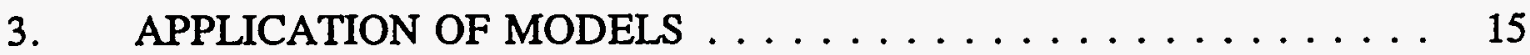

3.1 Model Applications $\ldots \ldots \ldots \ldots \ldots \ldots \ldots \ldots \ldots$

3.1 .1 Decision Support $\ldots \ldots \ldots \ldots \ldots \ldots \ldots \ldots$

3.1.2 Risk and Performance Assessment . . . . . . . . 15

3.1.3 Screening Analysis and Priority Setting . . . . . . . 16

3.1.4 Demonstration of Regulatory Compliance . . . . . . . 16

3.1.5 Determining Effectiveness and Extent of Remediation

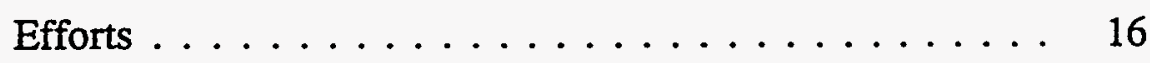


3.2 Model Limitations . . . . . . . . . . . . . . . . 17

3.2.1 Conceptual Model Uncertainty $\ldots \ldots \ldots \ldots \ldots \ldots 18$

3.2 .2 Parameter Uncertainty $\ldots \ldots \ldots \ldots \ldots$

3.2 .3 Numerical Uncertainty . . . . . . . . . . . . . . 18

3.2.4 Limitations in Computer and Human Resources . . . . . . 18

3.3 Misapplication of Models . . . . . . . . . . . . . . 19

3.3.1 Inappropriate Conceptualization . . . . . . . . . . . 19

3.3.2 Improper Use of Data . . . . . . . . . . . . . . 19

3.3.3 Misinterpretation of Model Results . . . . . . . . 20

3.3.4 Inappropriate Selection and Use of Models and Computer Codes . . . . . . . . . . . . . . . 20

3.3.5 Lack of Documentation and Technical Support . . . . . 20

3.3.6 Use of Models by Inadequately Trained Individuals . . . . 21

4. CURRENT EFFORTS IN FATE AND TRANSPORT MODELING $\ldots 23$

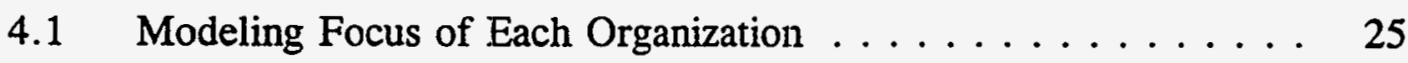

4.1.1 Department of Agriculture . . . . . . . . . . 25

4.1.2 Department of Defense . . . . . . . . . . . 26

4.1.3 Department of Energy $\quad \ldots \ldots \ldots \ldots \ldots \ldots . \ldots . \ldots 27$

4.1.4 Environmental Protection Agency $\ldots \ldots \ldots \ldots \ldots$

4.1.5 Nuclear Regulatory Commission . . . . . . . . . . 30

4.1 .6 National Science Foundation $\ldots \ldots \ldots \ldots \ldots$

4.1 .7 United States Geological Survey $\ldots \ldots \ldots \ldots \ldots$

5. ISSUES IN MODELING: RESEARCH AND DEVELOPMENT

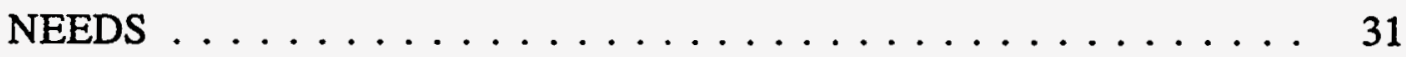

5.1 Improved Process and Numerical Modeling . . . . . . . 31

5.1 .1 Coupled Fate and Transport $\ldots \ldots \ldots \ldots \ldots \ldots . \ldots 32$

5.1.2 Multi-Phase Flow and Transport . . . . . . . . 33

5.1.3 Heterogeneities and Stochastic Fate and Transport

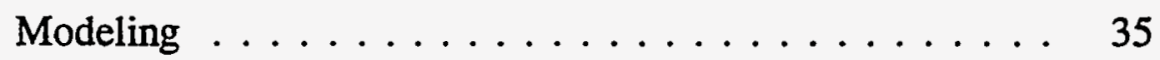

5.1 .4 Fracture Flow $\ldots \ldots \ldots \ldots \ldots \ldots \ldots \ldots \ldots \ldots$

5.1 .5 Numerical Solution Techniques . . . . . . . . . . 37

5.1.6 Influence of Remediation Efforts on Fate and Transport . . 38 
5.2 Improved Information Processing $\ldots \ldots \ldots \ldots \ldots \ldots$

5.3 Coordination of Model Development and Application . . . . . . 39

5.4 Summary and Recommendations $\ldots \ldots \ldots \ldots \ldots \ldots . \ldots 41$

6. CONCLUSIONS .................. 47

7. REFERENCES . . . . . . . . . . . . . . 49

Appendix A List of Current R\&D Fate and Transport Modeling Initiatives . . 53

Appendix B Primary DOE and EPA Fate and Transport Modeling R\&D

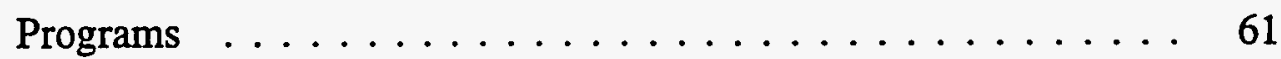

Appendix C Federal Research in Progress Database . . . . . . . . . 81 


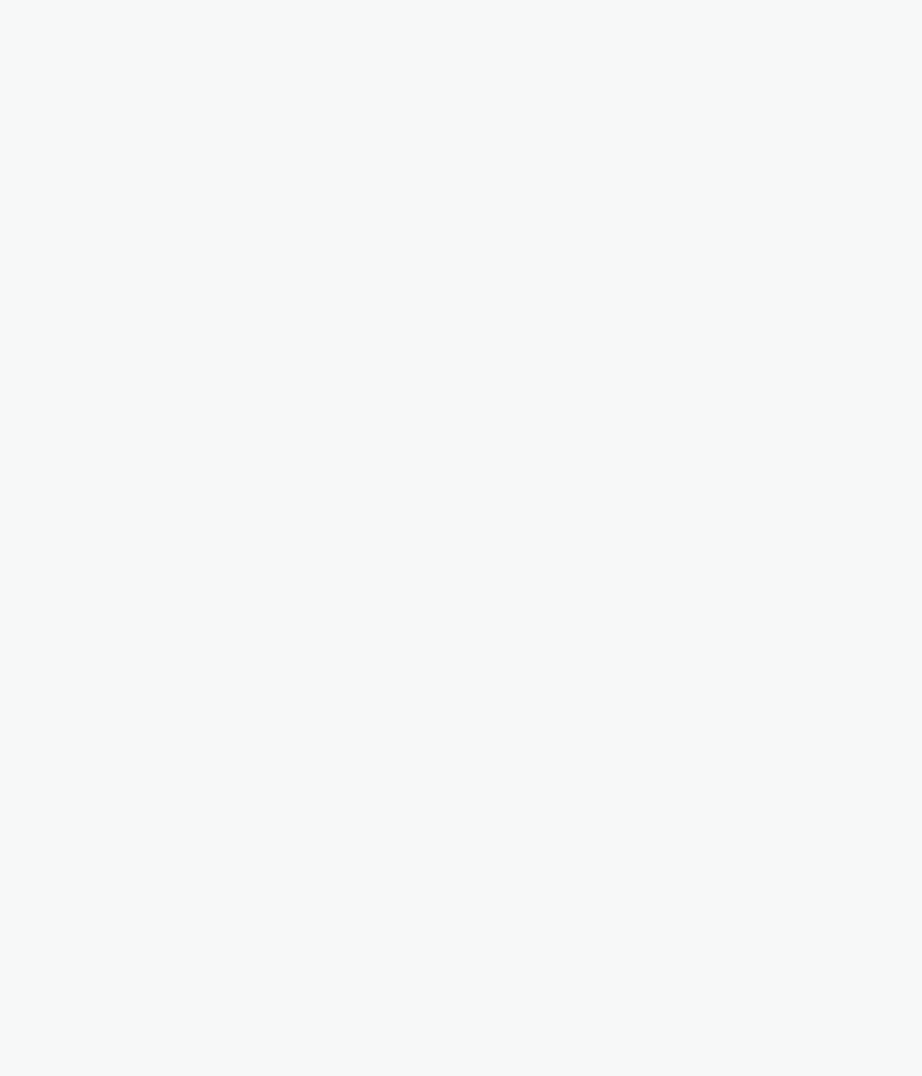




\section{LIST OF TABLES}

Table 2.1 Waste Type, Distribution, and Volume at DOE Sites . . . . . 7

Table 2.2 Combinations of Compound Classes of Contaminants Reported Most Frequently in Soils, Sediments and Groundwater at DOE Facilities (Adapted from Riley et al., 1992) _. . . . . . . . . . 9

Table 4.1 Summary of Modeling Programs Related to Subsurface Fate and Transport .................... 24

Table 5.1 Summary of Improvement Areas in Fate and Transport Modeling ................... 42

Table 5.2 Recommendations for Improved Model Development and Applications $\ldots \ldots \ldots \ldots \ldots \ldots \ldots \ldots \ldots$ 
.

. 


\section{ACRONYMS AND ABBREVIATIONS}

$\begin{array}{ll}\text { ARS } & \text { Agricultural Research Service } \\ \text { BNL } & \text { Brookhaven National Laboratory } \\ \text { CEAM } & \text { Center for Exposure Assessment Modeling } \\ \text { CSMoS } & \text { Center for Subsurface Modeling Support } \\ \text { DNAPLs } & \text { Dense Non-Aqueous Phase Liquids } \\ \text { DoD } & \text { Department of Defense } \\ \text { DOE } & \text { Department of Energy } \\ \text { EDSS } & \text { Environmental Decision Support System } \\ \text { EPA } & \text { Environmental Protection Agency } \\ \text { FEDRIP } & \text { Federal Research in Progress } \\ \text { GIS } & \text { Geographic Information System } \\ \text { GMS } & \text { Groundwater Modeling System } \\ \text { GWRTRAC } & \text { GroundWater Remediation Technologies Analysis Center } \\ \text { HAZ } & \text { Hazardous Waste } \\ \text { HLW } & \text { High-Level Waste } \\ \text { IMES } & \text { Integrated Model Evaluation System } \\ \text { LLW } & \text { Low-Level Waste } \\ \text { LNAPLs } & \text { Light Non-Aqueous Phase Liquids } \\ \text { MASTER } & \text { Midwest Agrichemical Surface/Subsurface Transport and Effects } \\ & \text { Research } \\ \text { MW } & \text { Mixed Waste } \\ \text { NAPLs } & \text { Non-Aqueous Phase Liquids } \\ \text { NAS } & \text { National Academy of Sciences } \\ \text { NASA } & \text { National Aeronautics and Space Administration } \\ \text { NIH } & \text { National Institutes of Health } \\ \text { NRC } & \text { Nuclear Regulatory Commission } \\ \text { NSF } & \text { National Science Foundation } \\ \text { ORNL } & \text { Oak Ridge National Laboratory } \\ \text { RSKERL } & \text { R.S. Kerr Environmental Research Laboratory } \\ & \end{array}$




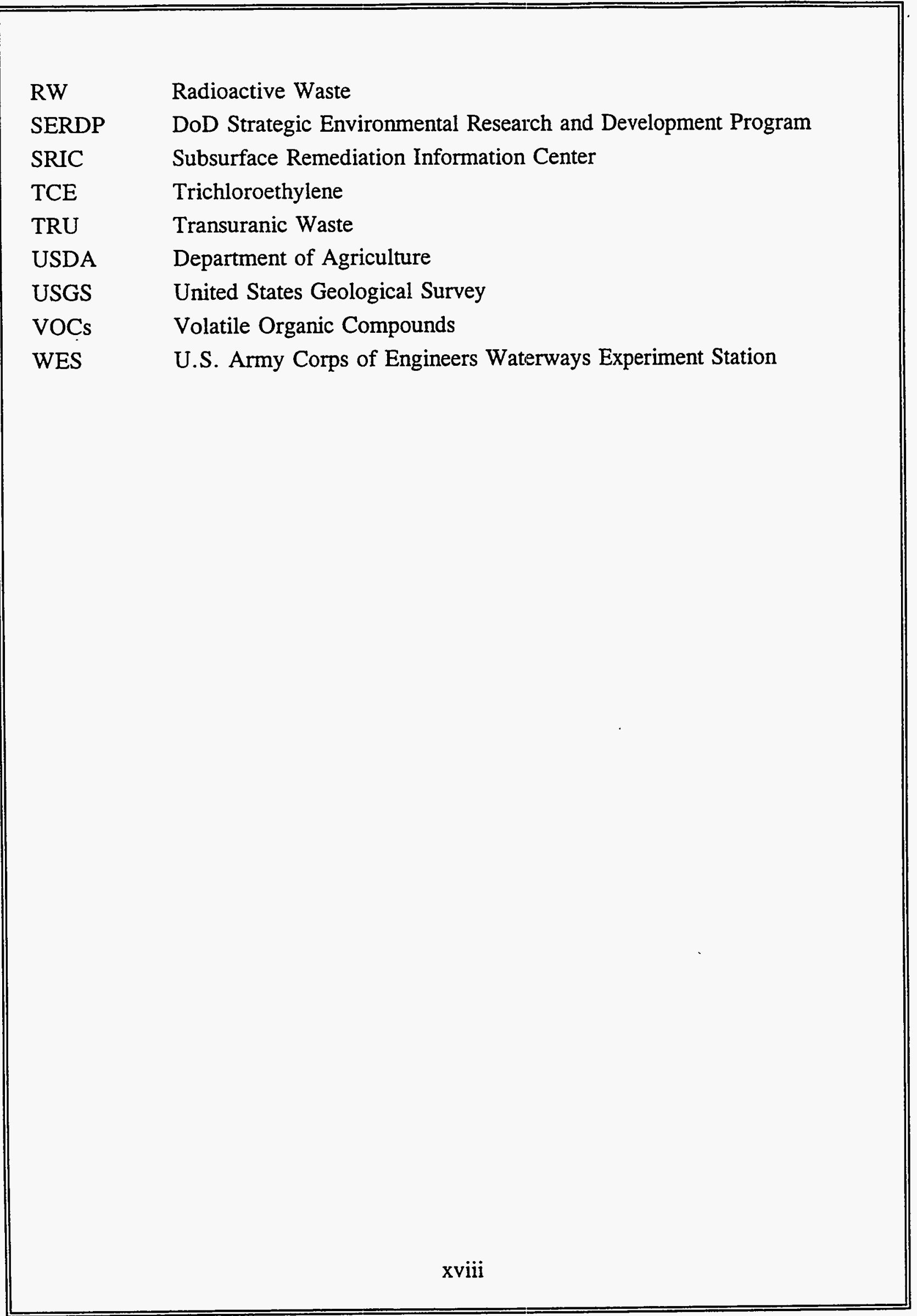




\section{INTRODUCTION}

The U.S. Department of Energy (DOE) is responsible for the remediation of over 450 different subsurface-contaminated sites. Contaminant plumes at these sites range in volume from a few to millions of cubic yards. The concentration of contaminants also ranges over several orders of magnitude. Contaminants include hazardous wastes such as heavy metals and organic chemicals, radioactive waste including tritium, uranium, and thorium, and mixed waste, which is a combination of hazardous and radioactive wastes. The physical form of the contaminants includes solutes, non-aqueous phase liquids (NAPLs), and vapor phase contaminants such as volatilized organic chemicals and radon.

To facilitate DOE efforts, information regarding the fate and transport of these contaminants is needed. This information is gained through the complementary and interactive processes of data collection (site characterization and monitoring) and predictive modeling. A model is a tool used to gain understanding of the system response to certain stresses and physical processes. They use the data that are collected to simulate contaminant migration, helping define the types and locations where additional data is required. The subsequent data can then be used to help confirm model predictions. The process continues until sufficient knowledge about the subsurface system has been obtained. Model predictions are often used as one component in the decision process pertaining to prioritization of needs, the approach and extent of remediation efforts, and compliance with regulatory criteria. The wide variety of contaminants, their physical, biological and chemical properties, and their subsurface environments make predictive modeling a complex and inexact process.

The objectives of this report are: 1) to present the results of a survey, completed in December 1994, of research and development work being performed to improve the mechanistic understanding of the processes that control movement of contaminants through subsurface systems, and 2) to identify areas for improvement and additional emphasis. The matter of contaminant fate and transport is a multi-disciplinary problem involving hydrology, geology, microbiology, chemistry, applied mathematics, computer science, operational research and others. In the framework of this report, no attempt has been made to perform a detailed technical review of any particular program. Instead, a detailed compilation of subsurface fate and transport modeling work being sponsored by Federal Agencies in the United States has been made.

Many other non-governmental organizations have substantial ongoing efforts in fate and transport modeling. These include the petroleum industry and many private companies 
that perform groundwater fate and transport analysis. In general, the private companies focus on applying and improving existing models to predict contaminant fate and transport. Their successes and failures should be reviewed to assist in defining model needs. However, the emphasis of this report is on new and improved model development. For this reason, projects conducted by private industry are not reviewed further here.

The second chapter of this report defines the scope of the contaminant transport problem. This is achieved by a general review of the source and types of contaminants, fluid flow processes in porous media, and transport processes. The review highlights the most important problems and their impacts on contaminant migration. The scope of this report is limited to subsurface contaminant transport modeling.

Often, the objective of predicting contaminant fate and transport is to evaluate the risks associated with the public's exposure to the contaminant. This involves coupling the output of the transport models to atmospheric flow models for gas phase release and other pathway models of aqueous phase releases, e.g., surface water flow, well-water ingestion, and plant uptake. The connection between subsurface contaminant migration modeling and dose/risk assessment modeling is also discussed in Chapter 2. In addition, the remediation process can cause substantial alteration of the flow and transport characteristics. The impacts of these changes on modeling needs are also examined.

The third chapter examines the various types of model applications. The level of detail in modeling can range from simple back-of-the-envelope calculations to sophisticated three-dimensional simulations of a multi-region, multi-phase flow and transport. The amount of information required, the desired accuracy of the prediction, and the ultimate use of the modeling results determine the selection of a particular model. This chapter discusses the various roles in which models are used to support environmental management efforts, general limitations of modeling, and misapplication of models.

Chapter 4 reviews current groundwater fate and transport modeling efforts and relates this work to contaminant plume remediation issues. The issue of groundwater flow and subsurface transport is significant in the United States. As such, many government organizations have substantial programs in this area. Government agencies that support fate and transport modeling efforts include the Environmental Protection Agency (EPA), Nuclear Regulatory Commission (NRC), U.S. Department of Agriculture (USDA), Department of Energy (DOE), National Science Foundation (NSF), Department of Defense (DoD), United States Geological Survey (USGS), and National Institute of Health (NIH). Appendix A provides a detailed list of ongoing modeling work related to subsurface fate and transport of contaminants.

Based on the findings described in this report, a list of areas in which fate and transport modeling may require further research and development is provided in Chapter 5. The recommendations are divided into three sections. The first section discusses needs related to improving modeling of the processes relevant to plume remediation. The second 
section is concerned with handling the large amounts of data needed to simulate and analyze subsurface contaminant transport. The final section suggests guidelines for effective coordination and partnering of the development and application of models. Chapter 6 provides the main conclusions reached as a result of this study. 



\section{SUBSURFACE CONTAMINANT TRANSPORT: PROBLEM DESCRIPTION}

The fate and transport of contaminants in subsurface systems depends on the physical, chemical, biological, and mechanical processes that occur. In general, this is a complex multi-disciplinary problem whose solution depends upon developing knowledge about each of these processes. This knowledge is used to develop a conceptual model of system behavior. The conceptual model is limited to the processes believed to be most important in controlling fate and transport under the expected range of environmental conditions, and will not contain all processes known to occur. From the conceptual model, a mathematical description of the system is constructed. This description may sometimes be solved analytically, but most often it is solved by translating the mathematical description into a form that can be processed through the use of numerical techniques.

The conceptual model of the system is problem-specific, as is its mathematical model. The objective of this section is to obtain a clear definition of the range of problems prior to defining the technical needs. This will improve our capability to understand contaminant fate and transport, and will involve defining contaminant sources and types, and the processes that control their migration. When remedial action is considered, the impact of the remediation process on contaminant transport must also be known.

Contaminant fate and transport depends on the source of contaminants, their type, e.g., solute, vapor phase and non-aqueous phase, and how they are released, e.g., from ponds, injection wells and solidified wastes. Sections 2.1 and 2.2 highlight the major contamination sources and types found at DOE and other sites.

Contaminant transport is influenced by several processes, including advection, dispersion, local geochemistry, microbial reactions, degradation, and mass transfer. For subsurface flow, advection with the fluid phase is typically the dominant mechanism for large scale movement of contaminants. Remedial actions often substantially alter the transport characteristics of the contaminants. A few of the more common remediation techniques will be discussed in Section 2.4 in terms of their impact on contaminant transport.

\subsection{Contaminant Sources and Types}

Thousands of contaminant plumes at DOE, DoD, Superfund and other sites will be remediated in the decades ahead. 'Many have not been completely evaluated, but the known 
extent and volume of waste is often extremely large. The current study specifically reviews contamination at DOE sites because the scope is large enough and the types of contamination are diverse enough to provide a general overview of contamination types.

\subsubsection{Technical Approach for Waste Classification}

The basis of this waste distribution survey is a database compiled by the DOE Office of Environmental Management from various DOE publications. The publications contain information about site location, type of contaminant (e.g., radioactive, organic, heavy metals or mixed) and extent of contamination. In some cases, the physical form of the waste was also given, e.g., mill tailings, sludge, concrete and groundwater. The volume and concentration of the contaminant was provided when available. To simplify waste classification for this evaluation the following assumptions were made:

a) Waste that contains only radioactive constituents will be classified as radioactive waste (RW) regardless of whether it is transuranic waste (TRU), low-level waste (LLW), high-level waste (HLW), tritium, Ra-226, Rn-222, or some combination of these.

b) Hazardous waste (HAZ) will consist of waste that contains hazardous constituents such as heavy metals, organics (including solvents), or some combination of these.

c) Mixed wastes (MW) are a combination of RW and HAZ waste. A special subclass includes mill tailings that contain $\mathrm{U}, \mathrm{Ra}-226, \mathrm{Rn}-222$, and heavy metals.

d) Gaseous wastes include volatile organic compounds (VOCs), tritium gas and Rn-222. The latter are mainly from mill tailings, as mentioned above.

e) Light non-aqueous phase liquids (LNAPLs) are less dense than water and include "large" amounts of organic liquids such as gasoline and oil. Dense non-aqueous phase liquids (DNAPLs) are denser than water and include many solvents such as carbon tetrachloride $\left(\mathrm{CCl}_{4}\right)$ and trichloroethylene (TCE). NAPLs are usually present as a separate liquid phase as well as in the gas and aqueous phases.

By knowing the quantities of waste and their modeling requirements, an estimate can be made of the overall scope of potential problems.

\subsubsection{Results of Waste Classification}

Table 2.1, derived from a database developed by DOE Office of Technology Development of about 460 waste site "units," describes the general nature, distribution, and approximate extent of the contamination. Contaminants may be present in different locations at the site (or operable unit). These include solid waste, soil or groundwater, a separate NAPL phase, or in some cases a gaseous phase. 
Table 2.1 Waste Type, Distribution, and Volume at DOE Sites

\begin{tabular}{|c|c|c|}
\hline $\begin{array}{c}\text { Contaminant Location at } \\
\text { Waste Site }\end{array}$ & $\begin{array}{c}\text { Number of Sites } \\
\text { Containing Various Waste } \\
\text { Types }\end{array}$ & $\begin{array}{l}\text { Extent/Volume (Cubic } \\
\text { Yards) of Contaminant }\end{array}$ \\
\hline \multicolumn{3}{|c|}{ ARID SITES } \\
\hline $\begin{array}{l}\text { Soil, Debris, Tailings, } \\
\text { Sludge, etc. }\end{array}$ & $\begin{array}{l}\text { RW - } 25 \\
\text { HAZ - } 58 \\
\text { MW - } 127\end{array}$ & $\begin{array}{l}>1.7 \times 10^{7}\left(\text { mainly } \mathrm{H}^{3}\right) \\
>5 \times 10^{5} \\
>3 \times 10^{8}\end{array}$ \\
\hline Groundwater & $\begin{array}{l}\text { RW - } 7 \\
\text { HAZ - } 42 \\
\text { MW - } 77\end{array}$ & $\begin{array}{l}\text { Insufficient data } \\
>>2 \times 10^{6} \\
>>5 \times 10^{7}\end{array}$ \\
\hline Gas Phase & $\begin{array}{l}\text { RW - undetermined } \\
\text { HAZ - undetermined } \\
\text { MW - undetermined }\end{array}$ & Insufficient data \\
\hline $\begin{array}{l}\text { DNAPLs and LNAPLs }{ }^{(1)} \\
\text { (Free Phase) }\end{array}$ & 32 & Insufficient data \\
\hline \multicolumn{3}{|c|}{ Non-Arid SITES } \\
\hline $\begin{array}{l}\text { Soil, Debris, Tailings, } \\
\text { Sludge, etc. }\end{array}$ & $\begin{array}{l}\text { RW }-16 \\
\text { HAZ - } 8 \\
\text { MW - } 62\end{array}$ & $\begin{array}{l}>2400 \\
\text { Insufficient data } \\
2 \times 10^{7}\end{array}$ \\
\hline Groundwater & $\begin{array}{l}\text { RW - } 6 \\
\text { HAZ - } 8 \\
\text { MW - } 48\end{array}$ & $\begin{array}{l}\text { Insufficient data } \\
\text { Insufficient data } \\
>>4.6 \times 10^{6}\end{array}$ \\
\hline Gas Phase & $\begin{array}{l}\text { RW - undetermined } \\
\text { HAZ - undetermined } \\
\text { MW - undetermined }\end{array}$ & Insufficient data \\
\hline $\begin{array}{l}\text { DNAPLs and LNAPLs }{ }^{(1)} \\
\text { (Free Phase) }\end{array}$ & 7 & Insufficient data \\
\hline
\end{tabular}

(1) Sites with NAPL contamination only. Does not include sites with mixed NAPLs and radioactive wastes; these are reported under mixed waste (MW). 
Relatively few of the sites contain RW alone, MW being the largest type by far. The extent of contamination provided in the data base is sometimes given as an areal value, and in other cases, the volume of contamination is provided in cubic yards. The last column in Table 2.1 is a summation of only the specified volumes that are given. Volume estimates that could not be obtained were not included in the summation, but MW is clearly the primary problem at DOE sites. Most waste is at the arid sites, and the largest volumes of contamination are in the soils followed by groundwater. The soils are believed to contain the largest waste proportion by weight since they usually constitute the original source of contamination.

Little information exists on the amount of gas phase contamination. However, many of the NAPL wastes are volatile and will also contaminate the gas phase. Any wastes containing substantial quantities of Radium-226 (i.e., mill tailings) will also contain the gas Radon-222. Tritium and carbon-14 also have the potential to exist in the gas phase.

Table 2.2 presents a compilation of the different types of co-contaminants found throughout the DOE sites, adapted from Riley et al., 1992. This table demonstrates the wide range of contaminant mixtures and highlights some of the more important mixtures. Riley et al., 1992, contains a more detailed analysis of contaminant mixtures, and their results may be used to identify the appropriate contamination problems to receive the focus of new modeling development activities.

\subsubsection{Special Considerations for Fate and Transport Modeling}

Modeling of RW and HAZ waste fate and transport via subsurface mechanisms is best understood when the contaminants migrate as a single solute in a porous medium. Numerous computer codes are able to quantify the source and transport mechanisms for saturated flow, but local heterogeneities often make prediction difficult. Estimates of solute transport through unsaturated media are even less accurate, and solute transport through fractured media estimates are a challenge because of lack of knowledge of fracture size and distribution. Lack of understanding of the chemical processes and rates of colloid formation makes colloid-facilitated transport problematic to model. Few attempts have been made to model multi-component transport, and multi-component, multi-species modeling is in its infancy.

For mixed waste, it may not always be possible to separate RW and HAZ calculations because of chemical interactions. This is further complicated by the large number of constituents and their chemical speciation, and lack of knowledge of concentration and spatial distribution of each constituent at the sites.

Gas phase modeling at waste sites is technically possible but requires extensive information on the nature of the site, including, soil porosity, moisture content, fracture characteristics of the host geology, and rates of biodegradation. Radon releases from mill tailing sites, tritiated water vapor, tritiated methane, gas phase $\mathrm{C}-14$ compounds, and VOC transport are relevant to this case. 
Table 2.2 Combinations of Compound Classes of Contaminants Reported Most Frequently in Soils, Sediments and Groundwater at DOE Facilities (Adapted from Riley et al., 1992)

\begin{tabular}{|l|c|c|l|c|c|}
\hline \multicolumn{1}{|c|}{ Soils/Sediments } & $\begin{array}{l}\text { No. of } \\
\text { Sites }\end{array}$ & $\begin{array}{c}\text { No. of } \\
\text { Facilities }\end{array}$ & \multicolumn{1}{c|}{ Class } & $\begin{array}{c}\text { No. } \\
\text { of } \\
\text { Sites }\end{array}$ & $\begin{array}{c}\text { No. of } \\
\text { Facilities }^{(2)}\end{array}$ \\
\hline Metals, radionuclides & 25 & 7 & $\begin{array}{l}\text { Metals, chlorinated } \\
\text { hydrocarbons }\end{array}$ & 38 & 12 \\
\hline Metals, PCBs & 18 & 6 & Metals, radionuclides & 36 & 11 \\
\hline $\begin{array}{l}\text { Metals, chlorinated } \\
\text { hydrocarbons }\end{array}$ & 16 & 9 & Metals, anions & 33 & 11 \\
\hline Radionuclides, PCBs & 15 & 4 & Anions, radionuclides & 33 & 10 \\
\hline $\begin{array}{l}\text { Chlorinated } \\
\text { hydrocarbons, fuel } \\
\text { hydrocarbons }\end{array}$ & 15 & 11 & $\begin{array}{l}\text { Radionuclides, } \\
\text { chlorinated hydrocarbons }\end{array}$ & 32 & 10 \\
\hline Anions, radionuclides & 14 & 8 & $\begin{array}{l}\text { Anions, chlorinated } \\
\text { hydrocarbons }\end{array}$ & 26 & 9 \\
\hline $\begin{array}{l}\text { Radionuclides, } \\
\text { chlorinated hydrocarbons }\end{array}$ & 14 & 6 & $\begin{array}{l}\text { Chlorinated } \\
\text { hydrocarbons, fuel } \\
\text { hydrocarbons }\end{array}$ & 17 & 7 \\
\hline $\begin{array}{l}\text { Chlorinated } \\
\text { hydrocarbons, PCBs }\end{array}$ & 13 & 6 & $\begin{array}{l}\text { Metals, fuel } \\
\text { hydrocarbons }\end{array}$ & 16 & 8 \\
\hline Metais, anions & 12 & 7 & Metals, ketones & 16 & 5 \\
\hline $\begin{array}{l}\text { Metals, fuel } \\
\text { hydrocarbons }\end{array}$ & 11 & 9 & $\begin{array}{l}\text { Radionuclides, fuel } \\
\text { hydrocarbons }\end{array}$ & 16 & 6 \\
\hline $\begin{array}{l}\text { Anions, chlorinated } \\
\text { hydrocarbons }\end{array}$ & 11 & 6 & $\begin{array}{l}\text { Chlorinated } \\
\text { hydrocarbons, ketones }\end{array}$ & 16 & 5 \\
\hline $\begin{array}{l}\text { Fuel hydrocarbons, PCBs } \\
\text { Metals, radionuclides, }\end{array}$ & 10 & 5 & $\begin{array}{l}\text { Anions, fuel } \\
\text { hydrocarbons }\end{array}$ & 12 & 5 \\
\hline $\begin{array}{l}\text { Metals, chlorinated } \\
\text { hydrocarbons, fuel } \\
\text { hydrocarbons }\end{array}$ & 8 & 8 & $\begin{array}{l}\text { Metals, anions, } \\
\text { radionuclides }\end{array}$ & 29 & 10 \\
chlorinated hydrocarbons & 29 & 10 \\
\hline
\end{tabular}


Table 2.2 (Cont'd) Combinations of Compound Classes of Contaminants Reported Most Frequently in Soils, Sediments and Groundwater at DOE Facilities (Adapted from Riley et al., 199.2)

\begin{tabular}{|l|c|c|l|c|c|}
\hline \multicolumn{1}{|c|}{ Soils/Sediments } & $\begin{array}{l}\text { No. of } \\
\text { Sites }\end{array}$ & $\begin{array}{c}\text { No. of } \\
\text { Facilities }\end{array}$ & \multicolumn{1}{c|}{ Class } & $\begin{array}{c}\text { No. } \\
\text { of } \\
\text { Sites }\end{array}$ & $\begin{array}{c}\text { No. of } \\
\text { Facilities }\end{array}$ \\
\hline $\begin{array}{l}\text { Metals, radionuclides, } \\
\text { chlorinated hydrocarbons }\end{array}$ & 11 & 6 & $\begin{array}{l}\text { Metals, anions, } \\
\text { chlorinated hydrocarbons }\end{array}$ & 25 & 9 \\
\hline $\begin{array}{l}\text { Metals, chlorinated } \\
\text { hydrocarbons, PCBs }\end{array}$ & 10 & 6 & $\begin{array}{l}\text { Anions, radionuclides, } \\
\text { chlorinated hydrocarbons }\end{array}$ & 23 & 9 \\
\hline $\begin{array}{l}\text { Metals, anions, } \\
\text { radionuclides }\end{array}$ & 9 & 6 & $\begin{array}{l}\text { Metals, chlorinated } \\
\text { hydrocarbons, ketones }\end{array}$ & 16 & 5 \\
\hline $\begin{array}{l}\text { Metals, anions, } \\
\text { chlorinated hydrocarbons }\end{array}$ & 9 & 6 & $\begin{array}{l}\text { Radionuclides, } \\
\text { chlorinated } \\
\text { hydrocarbons, fuel } \\
\text { hydrocarbons }\end{array}$ & 15 & 5 \\
\hline $\begin{array}{l}\text { Radionuclides, } \\
\text { chlorinated } \\
\text { hydrocarbons, PCBs }\end{array}$ & 9 & 4 & $\begin{array}{l}\text { Metals, radionuclides, } \\
\text { fuel hydrocarbons }\end{array}$ & 13 & 5 \\
\hline $\begin{array}{l}\text { Metals, fuel } \\
\text { hydrocarbons, PCBs }\end{array}$ & 7 & 5 & $\begin{array}{l}\text { Metals, chlorinated } \\
\text { hydrocarbons, fuel } \\
\text { hydrocarbons }\end{array}$ & 12 & 5 \\
\hline $\begin{array}{l}\text { Anions, radionuclides, } \\
\text { chlorinated hydrocarbons }\end{array}$ & 7 & 5 & $\begin{array}{l}\text { Metals, anions, fuel } \\
\text { hydrocarbons }\end{array}$ & 12 & 5 \\
\hline $\begin{array}{l}\text { Anions, chlorinated } \\
\text { hydrocarbons, fuel } \\
\text { hydrocarbons }\end{array}$ & 7 & 6 & $\begin{array}{l}\text { Metals, radionuclides, } \\
\text { ketones }\end{array}$ & 12 & 3 \\
\hline $\begin{array}{l}\text { Radionuclides, } \\
\text { chlorinated } \\
\text { hydrocarbons, fuel } \\
\text { hydrocarbons }\end{array}$ & 7 & 5 & $\begin{array}{l}\text { Anions, radionuclides, } \\
\text { fuel hydrocarbons }\end{array}$ & 11 & 4 \\
\hline $\begin{array}{l}\text { Metals, anions, } \\
\text { radionuclides, chlorinated } \\
\text { hydrocarbon }\end{array}$ & 7 & $\begin{array}{l}\text { Metals, anions, } \\
\text { radionuclides, chlorinated } \\
\text { hydrocarbons }\end{array}$ & 23 & 9 \\
\hline $\begin{array}{l}\text { Metals, radionuclides, } \\
\text { chlorinated } \\
\text { hydrocarbons, PCBs }\end{array}$ & 7 & 4 & $\begin{array}{l}\text { Metals, radionuclides, } \\
\text { chlorinated } \\
\text { hydrocarbons, fuel } \\
\text { hydrocarbons }\end{array}$ & 12 & 4 \\
\hline
\end{tabular}


Table 2.2 (Cont'd) Combinations of Compound Classes of Contaminants Reported Most Frequently in Soils, Sediments and Groundwater at DOE Facilities (Adapted from Riley et al., 1992)

\begin{tabular}{|l|c|c|l|c|c|}
\hline \multicolumn{1}{|c|}{ Soils/Sediments } & \multicolumn{3}{c|}{ Groundwater } \\
\hline $\begin{array}{l}\text { Class } \\
\text { Sites }\end{array}$ & $\begin{array}{c}\text { No. } \\
\text { Facilities }^{(2)}\end{array}$ & \multicolumn{1}{|c|}{ Class } & $\begin{array}{c}\text { No. } \\
\text { of } \\
\text { Sites }\end{array}$ & $\begin{array}{c}\text { No. of } \\
\text { Facilities }^{(2)}\end{array}$ \\
\hline $\begin{array}{l}\text { Metals, anions, } \\
\text { radionuclides, alkyl } \\
\text { phosphates }\end{array}$ & 5 & 4 & $\begin{array}{l}\text { Metals, radionuclides, } \\
\text { chlorinated } \\
\text { hydrocarbons, ketones }\end{array}$ & 12 & 3 \\
\hline $\begin{array}{l}\text { Metals, anions, } \\
\text { chlorinated } \\
\text { hydrocarbons, fuel } \\
\text { hydrocarbons }\end{array}$ & 5 & 5 & $\begin{array}{l}\text { Metals, anions, } \\
\text { radionuclides, fuel } \\
\text { hydrocarbons }\end{array}$ & 11 & 4 \\
\hline $\begin{array}{l}\text { Metals, anions, } \\
\text { chlorinated } \\
\text { hydrocarbons, PCBs }\end{array}$ & 5 & 4 & $\begin{array}{l}\text { Metals, anions, } \\
\text { chlorinated } \\
\text { hydrocarbons, ketones }\end{array}$ & 11 & 3 \\
\hline $\begin{array}{l}\text { Metals, radionuclides, } \\
\text { chlorinated } \\
\text { hydrocarbons, fuel } \\
\text { hydrocarbons }\end{array}$ & 5 & 5 & $\begin{array}{l}\text { Metals, chlorinated } \\
\text { hydrocarbons, fuel } \\
\text { hydrocarbons, ketones }\end{array}$ & 11 & 3 \\
\hline
\end{tabular}

(1) Number of waste sites (out of 91) reporting specific class combination.

(2) Number of facilities (out of 18) reporting specific class combination.

NAPL behavior is much more difficult to model than groundwater flow. The formation of a separate liquid phase and the potential for interphase transfer i.e., volatilization, dissolution, and sorption to the solid matrix, significantly increase the complexity of the analysis.

For all of the above situations, the accuracy of modeling calculations will be strongly dependent on knowledge of site hydrogeology, geochemistry, microbiology, and chemical kinetics. Without such data, uncertainty analyses must be performed to define the potential range of outcomes. The absence of quality data often requires conservatism to be included in fate and transport analysis, leading to higher remediation costs.

\subsection{Fluid Flow Processes}

Contaminant movement is generally dependent on advection in the fluid phases i.e., liquid and gas. Therefore, it is critical to determine the velocity at which fluid phases move. In a subsurface system, there are three general types of fluids that may undergo substantial migration over time: water, air (vapor), and NAPLs. The migration of each of these phases 
depends on the driving forces for each phase, such as pressure and gravitational gradients, the subsurface properties and their spatial distributions related to flow such as permeability and system geometry (e.g., presence of fractures, different geologic units), and the initial distribution of each phase.

The movement of liquid phases is expressed using a hydraulic conductivity that depends on permeability of the porous medium and fluid properties, such as viscosity and density. Liquid flow also depends on the degree of saturation in each phase; that is, the conductivity of the non-aqueous phase depends on the degree of saturation of the air and water phases. Often, the conductivity shows spatial variability due to local changes in the porous medium such as pore size, porosity, and grain size, which cause flow rates to vary locally around the mean flow rate. This leads to dispersion, and for NA.PLs and solutes, this can be observed as fingering of the plume.

Vapor phase movement also depends somewhat on the degree of saturation of each of the phases, but this factor is often neglected because the dependence is generally weak. Vapor phase movement is subject to atmospheric pressure changes and the flow properties of the soil. If the porous media are fractured, vapor flow can occur at large rates (e.g., meters per day) due to barometric pressure variations.

Generally, a flow equation is prepared for each of the phases present in the system. For flow, these equations are coupled through the hydraulic conductivity expressions that are a function of the degree of saturation of each phase. In addition, mass transfer between phases can occur, e.g., evaporation/condensation of water and volatilization of organics. When interphase mass transport is important, the flow equations for each phase must be solved simultaneously.

The most common approach to modeling flow is to obtain average flow rates through the subsurface environment. This procedure can be adequate for management of water resources, but when transport of contaminants become an issue, preferential flow paths due to heterogeneities become important.

Another major issue in fluid flow occurs when fractures are present. In the unsaturated zone, moisture is typically held in the small capillary pores of the medium, and the larger fractures are essentially dry. In this case, flow and transport take place through the pores. However, episodic infiltration events can cause the pores to temporarily fill with water, When this occurs, excess water flow is transmitted through the fractures. The high permeability of the fractures permits rapid transport of fluids as well as dissolved contaminants. In the saturated zone, both the fractures and pores are filled with fluid. Again, the fractures supply a pathway for relatively rapid fluid and contaminant movement.

\subsection{Transport Processes}

Contaminant movement is typically modeled by treating the subsurface system as a continuum and performing a mass balance over a representative volume for each fluid phase 
that contains the contaminant. The contaminant mass balance equates the rate of change in mass with the amount of mass added or removed from the volume due to: 1) Transport processes (advection, dispersion, diffusion); 2) degradation processes (radioactive decay, biotransformation, chemical transformation); 3) transfer between phases (production of gases by biodegradation, volatilization and condensation), and 4) external sources or sinks such as extraction wells and release from wastes. This approach results in the well-known advection dispersion transport equation.

An alternative approach to the advection dispersion transport model is the particle tracking method, in which movement of fictitious contaminant particles through the subsurface system is tracked. The process provides a distribution of outcomes from which the system behavior can be estimated. Using a particle tracking approach rather than the continuum approach allows heterogeneities to be directly incorporated into the transport equations.

The complexities involved with attempting to predict transport in natural systems are related to the spatial variability of the system, as well as to the number of potential interactions that can occur. In many instances, this natural variability greatly affects fate and transport. For example, the general formulation for contaminant transport requires knowledge about the rates of all geochemical and biological reactions, interphase mass transfer, and parameter values for the advection velocity, chemical sorption, and dispersion, at all locations within the domain under consideration. For natural systems, there are a wide range of chemical species in the system and the rate constants for all possible reactions may not be known.

Similar limits apply to interphase mass transfer. The lack of knowledge leads to assumptions that permit the model to be developed only in terms of known quantities. For chemical reactions, it is often assumed that the system is in thermodynamic equilibrium. This allows the parameters in the equation to be described by known equilibrium constants, but the assumption must be justified, since it is not always valid. If reaction rates are slow and equilibrium is not reached, erroneous predictions will occur with this approach and kinetic rates should be used in the model.

Currently, substantial efforts are being performed to enhance the general understanding of subsurface contaminant fate and transport. A major emphasis has been placed on stochastic modeling. In this approach, parameter values are assigned random values consistent with the distribution of the parameter. Often the model is exercised several times with a different realization of input parameters. The output is then a range of possible outcomes that are consistent with the data. For example, hydraulic conductivity is known to exhibit substantial variability. If field measurements of the conductivity are taken, this data can be used to estimate the mean value as well as the distribution around the mean. The data can be incorporated into a model that predicts flow by assigning a unique value of conductivity to each computational point in the model. The estimated conductivity values would be selected such that the mean value and other statistical measures of the data, such as standard deviation, are preserved. 


\subsection{Role of Remediation in Altering Flow and Transport}

Remediation processes are developed to assist in treating contaminated sites. There are three basic types of remediation processes: those that attempt to remove the contamination, those that attempt to immobilize it, and those that attempt to (bio)-chemically transform the pollutants to a less hazardous substance. Removal processes include vapor vacuum extraction, pump-and-treat, air sparging, and steam sparging. Remediation techniques that attempt to immobilize the contamination include physical and chemical reaction, and containment, e.g., grout curtains and soil freezing.

Each of these processes will alter the local environment and therefore, their effects on flow and transport need to be assessed. This requires special models that focus on the important processes of the remediation technique being used. For example, surfactants are often used to increase the mobility of NAPLs. To properly understand the role of surfactants in enhancing remediation efforts, it is important to know the optimum method to introduce surfactants to subsurface systems, their transport characteristics, and their ability to mobilize the NAPLs.

Currently, pump-and-treat systems are frequently used in remediation. While modeling of these systems can be used to improve the effectiveness of remediation, the models are often overly optimistic in their assessment. Models often predict that the contaminant will be completely removed as pumping continues. However, experience shows that contaminant concentrations can only be reduced to a certain level. The cause of this behavior is not well understood, but several possible factors that could be responsible include diffusion into deadend pores, clay layers or fractures, matrix diffusion, and poor understanding of the sorption process.

\subsection{Connection with Risk Assessment Models}

Often, the ultimate concern about radioactive or hazarclous waste disposal is the effects that the contaminants will have on human health and the environment. Subsurface fate and transport modeling is a crucial component to estimating the risks of disposal and outcomes of remediation alternatives. The estimate of dose or risk for liquid phase contaminants requires taking the predicted concentration at the consumption well or surface water and using this as input to the pathway models from aqueous phase releases, such as surface flow, well-water ingestion, and plant uptake. The pathway models take this concentration and estimate the dose or risk. Similarly, for gas phase release, the concentration entering the atmosphere through the subsurface pathway is used as input to the atmospheric transport models and pathway models, such as inhalation and ingestion models, that estimate exposure risk. 


\section{APPLICATION OF MODELS}

A model is a tool used to gain understanding of the response of a system to certain stresses and physical processes. The level of detail in modeling can range from simple calculations to sophisticated three-dimensional simulations of a multi-region, multi-phase flow and transport. The amount of information required, the desired accuracy of the prediction, and the ultimate use of the modeling results will determine the selection of a particular model. This chapter presents a discussion of the applications, limitations, and misapplication of models. This discussion will set the framework for guidelines to develop and oversee fate and transport models.

\subsection{Model Applications}

The intended use of a model determines its sophistication and supporting data. The major uses of models in remediation programs include:

- Decision Support

- $\quad$ Risk and Performance Assessment

- $\quad$ Screening Analysis and Priority Setting

- Demonstration of Regulatory Compliance

- Determining Effectiveness and Extent of Remediation Efforts

\subsubsection{Decision Support}

There has been an emerging trend to incorporate fate and transport models, cost benefit models, and optimization techniques into a unified decision support system. These systems are collections of models designed to evaluate the effects of different remedial alternatives on system performance. The objective of a decision support system is to minimize costs such as social, political, and economical, subject to certain constraints, i.e., performance measures. The fate and transport models are responsible for calculating performance measures such as well water concentrations or release to surface waters.

\subsubsection{Risk and Performance Assessment}

Risk and performance assessments are essentially identical processes. Both are quantitative analyses that predict the release, transport, and human consumption of contaminants. The major conceptual difference between the two approaches is that radiological perils are defined by the estimated dose, while hazardous perils are defined by the estimated risk of incurring a 
health effect. Risk and performance assessment models are general procedures capable of evaluating the system behavior over a wide range of environmental conditions and data. As such, they are useful in initial site modeling, guiding site characterization efforts, and demonstrating compliance with regulations.

\subsubsection{Screening Analysis and Priority Setting}

Screening analysis typically uses simple models that are capable of predicting major trends. The objective of a screening model is to determine the important parameters controlling migration and general system behavior. Screening analyses are not intended to serve as the final assessment. Use of screening models for final assessment is an improper use of the models and can lead to inadequate decisions. The appropriate use of screening models does not always require site-specific data; generic data from similar systems may be used for preliminary estimates. However, use of non-site-specific data leads to large uncertainties in the predictions and can be misleading. To overcome this, additional site-specific data may be used, which leads to more confidence in the predictions.

Screening analyses are often performed in the early stages of site characterization and remedial action. As such, they can be used to guide further site characterization and set priorities. Screening analysis may stop short of conducting an entire risk/performance assessment. Often, a subset of the problem is simulated instead. For example, rather than calculating health effects through the groundwater, surface water, and food chain pathways, a screening analysis may use the concentration at a well as its basis for comparison between different scenarios.

\subsubsection{Demonstration of Regulatory Compliance}

Compliance demonstration often requires predicting the performance of the system over extended time frames, perhaps hundreds of years or longer. It is therefore impossible to experimentally demonstrate system performance. Instead, mathematical models are used. When demonstrating regulatory compliance for radioactive wastes, the process is defined as a performance assessment. For hazardous wastes, the process is defined as a risk assessment.

The level of detail required in modeling a system depends on the complexity of the system and the importance of the model in assessing performance. For example, if regulatory compliance can be demonstrated without taking credit for sorption and solubility limits, extremely simple models can be used to estimate these processes. This is typically not the case, however. In most simulations, credit must be obtained for the chemistry in providing sorption or solubility limits. In obtaining a defensible solubility limit, experimental measurements on site-specific systems and detailed geochemical modeling may be required.

\subsubsection{Determining Effectiveness and Extent of Remediation Efforts}

When modeling is used to define the extent and effectiveness of remediation efforts, a range in the sophistication of models may be used. In the early stages of site characterization, 
relatively simple models will be used to define the extent of the problem and guide further data collection. As more data become available, the conceptual model of the site can be improved, and models that more accurately represent the physical system in greater detail can be used.

When using models to help define the extent of remedial actions, attempts should be made to obtain the best estimate of system performance. This best estimate should include an evaluation of the uncertainty in the predictions and the likelihood for other possible outcomes. With all of this information, the decision on how to proceed becomes more quantitative and less empirical. In contrast, bounding predictions, which use overly conservative data and models, lead to predictions that indicate more corrective action than is necessary. In addition, using relatively simple models with little site characterization data as a basis for selecting remedial actions leads to results that are subject to large uncertainties and poor decisions are often made based on the results. This practice should be eliminated.

When modeling is used to assist in making remediation decisions, an iterative process can be used. It could combine: 1) forward modeling to predict system performance; 2) inverse modeling to help test and calibrate modeling conceptualizations and data selection against measured data; 3) and optimization which uses the modeling results to improve model and data selection for future estimates of system performance. This integrated approach can be used to help build confidence in model predictions.

\subsection{Model Limitations}

A model is a mathematical tool used to simulate the behavior of a complex physical system. As an approximation it has limitations, and there can be situations when model predictions do not represent field conditions with sufficient accuracy. It is crucial that the decision maker know the degree of confidence that should be placed in any model prediction.

In attempting to estimate the fate and transport of contaminants in subsurface systems, there are a number of limitations that lead to uncertainties in the evaluation. Model limitations can be grouped as follows:

- $\quad$ Conceptual model uncertainty;

- Parameter uncertainty;

- Numerical uncertainty; and

- Limitations in Computer and Human Resources

Efforts should be made to understand all sources of uncertainty and how these uncertainties impact on predicted system behavior. Currently, very little work has been performed to address conceptual model uncertainty. Many believe that conceptual uncertainty is the largest source of uncertainty in many model applications. Conceptual model uncertainties are difficult to evaluate. However, efforts have been made to address parameter and numerical uncertainty. 


\subsubsection{Conceptual Model Uncertainty}

Conceptual model uncertainty arises from an incomplete understanding of the system. Defining the conceptual model is a critical step in modeling subsurface fate and transport. The conceptual model should be consistent with available data, and should be refined as more data are collected. For example, as a first estimate, the conceptual model of a system could assume that the subsurface system can be represented as a uniform porous medium. As more data are collected, this conceptualization could change to non-uniform porous media, or fractured porous media. If the data indicate that there is a significant fracture system in the subsurface environment, flow and transport will be very different than assumed in the original conceptual model. Additional examples of refining the conceptual model would include incorporation of models for important geochemical or microbial reactions.

\subsubsection{Parameter Uncertainty}

Parameter uncertainty occurs from the complexity of the natural systems, natural property variability in space and time, lack of data, and measurement errors. All of these contribute to uncertainty in the choice of parameters, and therefore uncertainty in the estimated system performance. Lack of data is often a problem for subsurface systems where data collection is limited to a few locations. Interpolation of data is often performed between data collection points. The effect of parameter uncertainty on predicted system behavior can be estimated through repeated use of the model while sampling over the range of expected parameter values. Finally, complex kinetics of certain processes prevents proper identification and definition of process parameters. This reality is referred to as process uncertainty.

\subsubsection{Numerical Uncertainty}

Numerical uncertainty originates from simplification of the mathematical representation of the system into a form useful for estimating performance. For example, mass transport can be described using a partial differential equation. To solve this equation numerically, a series of assumptions are made to change the partial differential equation into a system of algebraic equations. Often the equations that represent system performance must be solved by an iterative procedure until a pre-defined convergence criteria is met. In this case, there is uncertainty about how well the iterative approximation to the solution of the differential equation will match the solution. Numerical uncertainties also arise due to discretization of the equation into finite spatial and temporal regions, as well as numerical dispersion introduced by the discretization.

\subsubsection{Limitations in Computer and Human Resources}

Other model limitations include the large computer requirements needed for some field-scale problems. Fate and transport calculations are sometimes performed at over a million different spatial locations or nodes. This requires the use of super-computers or parallel processing machines, and simulations can be expensive. Large computer requirements can also occur when modeling coupled hydro-geochemical transport. In addition, the use of these 
specialized machines limits the number of analysts qualified to perform the calculations. The use of parallel processing machines to simulate flow and transport is a developing field. As such, new techniques are needed to solve large-scale systems and efficiently use the different processors of parallel machines.

\subsection{Misapplication of Models}

Improper model application, unfortunately, happens much too often with the various problems encountered in environmental restoration and waste management. This frequently results in acting on decisions that prove to be inadequate once implemented, and often leads to unnecessarily high costs of remediation. This is generally due to overestimating the risk related to contaminant transport and the lack of properly representing complex naturally occurring geochemical and biological attenuation. An important and continued effort is needed to educate regulators, decision-makers and the public about the benefits and cost savings that can be achieved from the development and use of applicable, not only available models, and from the adequate selection and training of personnel involved in environmental modeling.

Although a model is capable of adequately representing subsurface contaminant fate and transport, it must be applied properly. Problems may arise from:

- Inappropriate conceptualization of the system;

- Improper use of data;

- Misinterpretation of model results;

- Inappropriate selection and use of models and computer codes;

- $\quad$ Lack of documentation and technical support; and

- Use of models by inadequately trained individuals

\subsubsection{Inappropriate Conceptualization}

Inappropriate conceptualization occurs when one or more processes important to predicting flow and transport are omitted from the model. For example, vapor phase transport may move contaminants large distances at rates much faster than in the liquid phase. If it is assumed that transport is only in the liquid phase, contaminant migration may be poorly represented for volatile species. Another common inappropriate conceptualization occurs when modeling complex subsurface hydraulic systems in one spatial dimension. This will neglect to incorporate preferential flow paths.

\subsubsection{Improper Use of Data}

Improper use of data occurs frequently when there is insufficient site-specific data for the subsurface system. The lack of site-specific data forces analysts to use data collected under different environmental conditions from the literature. Once the data are selected, they are often treated as appropriate for the system under study. Commonly, there is no documented discussion of the data selection or the reasons for its selection. Attempts to compare the 
environmental conditions under which the data were obtained and the systems environmental conditions are generally not made. In addition, there is often no attempt to define the degree of certainty with which the selected data and subsequent model results apply to the system under study.

\subsubsection{Misinterpretation of Model Results}

One of the main causes of misinterpretation of model results occurs when erroneous or inappropriate data are used to model the system. This is the classic "garbage in, garbage out" problem. However, once a computer prints out the "answer," no further thought is given to the degree of confidence that may be placed on that answer. Another misinterpretation of model results occurs when the peak contaminant concentrations at a downstream point or surface water body occur at the end of the problem simulation. Often, due to chemical retardation, the time for the peak to reach the down stream point is hundreds or thousands of years. If the calculation is terminated prior to the mean travel time of the contaminant, the peak concentration will not be reached until after the end of the simulation time, and will remain unknown.

\subsubsection{Inappropriate Selection and Use of Models and Computer Codes}

Often, generic one-dimensional or analytical transport models are used to simulate complex site-specific transport conditions for costly remedial investigation and design applications. Generally, these simple models are only acceptable as screening tools. In most cases, detailed site-specific data should be collected and modeling tools with sufficient complexity to represent site features are required. Unfortunately, decision-makers do not have an adequate background to make the proper judgement as to what level of detail and complexity is needed in the model. Often, their decision to accept inadequate modeling studies are forced by the lack of technically capable individuals or immediate budgetary and time constraints.

The opposite situation is also common and occurs when modeling contaminant fate and transport in complex geohydrologic systems with limited data. In many instances, a very sophisticated groundwater flow and transport model is used to represent the system. However, in the absence of detailed data, it would be more appropriate to use a simpler model that is consistent with the amount of available data. In all cases, expert judgement by trained individuals is necessary to decide the appropriate use of the models. The level of modeling detail should never exceed the level of detail of the available data and should be adequate for the intended use of the results.

\subsubsection{Lack of Documentation and Technical Support}

Most models are developed under research projects funded by government or university programs. These models are developed to implement or adapt new theories and techniques, or to serve in representing and evaluating experimental research data. Very often, due to limited funding and time, the models produced under such conditions remain poorly documented and unsupported. However, many of these codes are very powerful tools and do 
make it to the user community. Nevertheless, lack of documentation and technical support frequently lead to improper understanding of model limitations and misinterpretation of the results.

\subsubsection{Use of Models by Inadequately Trained Individuals}

Misinterpretation of model results is most likely to occur when models are used by inadequately trained individuals. Insufficient training often leads to a lack of understanding of the models and their underlying limitations and assumptions. This may lead to improper use of models and data. Frequently in the field, the desire to obtain an answer quickly causes the decision-makers to use whatever resources that are immediately available. This often leads to using untrained staff and improper application of the models.

Modeling contaminant fate and transport in complex subsurface systems requires the analyst to make a number of assumptions pertaining to the physical, chemical, and biological processes to model, and the data to simulate these processes. These choices are made based upon the analyst's expert knowledge and the available models and data. The analyst should clearly document the justification for selecting the model. However, this step is rarely performed at an adequate level. 


\section{CURRENT EFFORTS IN FATE AND TRANSPORT MODELING}

Contamination of groundwater is a major environmental concern in the United States.

Several government organizations have substantial programs examining contaminant fate and transport modeling. These agencies include the U.S. Department of Agriculture (USDA), Department of Defense (DoD), Department of Energy (DOE), Environmental Protection Agency (EPA), Nuclear Regulatory Commission (NRC), United States Geological Survey (USGS), National Institutes of Health (NIH), and National Science Foundation (NSF). The emphasis of programs varies depending on the mission of the organization. For example, in fate and transport modeling, the USDA is heavily concerned with the transport and biodegradation of pesticides, while the NRC is more involved in investigating radionuclides. The following chapter outlines aspects of the missions of each of these groups in contaminant fate and transport modeling, and presents a compilation of currently funded work in this area.

In addition, private industry conducts research in fate and transport modeling. For example, the American Petroleum Institute funds several programs involved in modeling fate and transport of hydrocarbons. Private industry also conducts a number of fate and transport assessments to support remedial investigation/feasibility studies, site characterization, and fate and transport studies. These studies tend to be more focused on model application than model development and will not be considered further in this report.

Table 4.1 provides a summary of currently funded initiatives that have a major emphasis on model development or new application of models. It is a compilation containing over 150 modeling initiatives and is based on a review of a number of sources, including program summary documents from DOE Office of Technology Development, DOE Subsurface Science program, and EPA's R.S. Kerr Laboratory Programs, a computerized literature search of the Federal Research in Progress Database, personal communications with researchers at several National Laboratories, and discussions with personnel from several Federal Agencies (DOE, NRC, and EPA). This summary represents the projects identified as part of this study and attempts to determine the major areas of emphasis in fate and transport modeling. It is not an exhaustive list of all projects being performed through funding by U.S. government agencies.

Details of the compilation are provided in three appendices. In Appendix A, for each project summarized in Table 4.1, a brief project title, the performing organization and the funding 
Table 4.1 Summary of Modeling Programs Related to Subsurface Fate and Transport

\begin{tabular}{|c|c|c|}
\hline Focus Area & Number & Funding Agency \\
\hline Barrier Emplacement Design & 2 & DOE, DoD \\
\hline Bioremediation/Biodegradation & 7 & DOE, EPA, DoD \\
\hline Database & 3 & DOE, EPA, USDA \\
\hline Decision Support/Optimization & 16 & USDA, EPA, DOE, NSF, DoD \\
\hline Electrokinetic Enhanced Transport & 3 & DOE, NSF, DoD \\
\hline \multicolumn{3}{|l|}{ Flow and Transport } \\
\hline Colloid Transport & 3 & DOE, USDA \\
\hline Fracture Flow & 7 & USGS, EPA, DOE, NRC, NIH \\
\hline Groundwater Management & 19 & USDA \\
\hline International Programs & 2 & DOE \\
\hline Microbial Transport & 6. & DOE, USDA \\
\hline Multi-Component Solute Transport & 7 & DOE, EPA, NRC, DoD \\
\hline $\begin{array}{l}\text { Multi-Phase, Multi-Component } \\
\text { Transport }\end{array}$ & 22 & $\begin{array}{l}\text { DOE, EPA, NSF, USGS, USDA, } \\
\text { DoD }\end{array}$ \\
\hline Pesticide Transport & 12 & USDA \\
\hline Solute Transport & 16 & $\begin{array}{l}\text { NSF, USGS, EPA, USDA, NH, } \\
\text { DOE, DoD }\end{array}$ \\
\hline Stochastic Flow and Transport & 13 & DOE, NSF, USGS, USDA, NIH \\
\hline Total Flow and Transport & 107 & \\
\hline GIS Systems & 3 & USDA \\
\hline Molecular Scale Chemical Modeling & 1 & DOE \\
\hline Numerical Techniques & 9 & NSF, DOE, DoD \\
\hline Optimal Data Collection & 9 & DOE, NSF, USGS, DoD \\
\hline Technical Transfer & 4 & EPA, DOE, USDA, DoD \\
\hline Visualization & 2 & DoD, NSF \\
\hline
\end{tabular}


agency is supplied. Appendix B provides information on DOE- and EPA-funded projects with a brief abstract of each program and when available, the level of effort. Appendix $C$ provides information on the Federal Research in Progress database. This database includes over three hundred projects related to subsurface fate and transport modeling, the approximately 150 projects incorporated in Table 4.1 and another 150 initiatives that have a primary emphasis on experimental data collection with a secondary emphasis on modeling to assist in data interpretation. This database includes information on the funding agency, the performing agency, and a detailed abstract of each program.

From Table 4.1, it is apparent, based on the number of projects listed in each category, that major emphasis is being placed on the following areas:

- Decision Support Systems

- Groundwater Management

- Multi-Phase, Multi-Component Transport

- $\quad$ Solute Transport

- $\quad$ Stochastic Modeling

Less but not unsubstantial emphasis is being placed on improvement of models in the following areas: bioremediation/biodegradation, fracture flow, multi-component multi-species solute transport, microbial transport, pesticide transport, improved numerical solution techniques, and optimal design and data collection models. Other model development areas that have a few funded projects include modeling of flow through viscous barriers, database development, electrokinetic enhanced transport, colloid facilitated transport, development of geographical information systems (GIS), technical transfer, and visualization techniques (graphical representation).

\subsection{Modeling Focus of Each Organization}

\subsubsection{Department of Agriculture}

The U.S. Department of Agriculture (USDA) conducts a substantial amount of research into subsurface contaminant fate and transport. Their major mission is to research the following areas pertaining to water quality: 1) determine fate and transport of nutrients and pesticides in the soil and minimize invasion into groundwater; 2 ) improve management of riparian areas adjacent to streams and ponds; 3 ) develop management systems using cover crops and rotations to eliminate contamination of water supplies; and 4) assess mutagenicity of natural and manufactured contaminants.

Research is conducted primarily by universities and the Agricultural Research Service, which has several offices located throughout the United States. The work they perform that is relevant to fate and transport modeling involves examining processes related to the migration of nutrients and pesticides. The USDA also funds research in decision support systems, geographical information systems (GIS), and microbial, multi-phase, and stochastic transport. 


\subsubsection{Department of Defense}

The Department of Defense (DoD) is in charge of over 10,000 contaminated sites at more than 1200 installations, many of which will require groundwater cleanup. In 1992, studies by the National Academy of Sciences (NAS) and internal DoD advisory boards recommended that DoD greatly increase their groundwater modeling capabilities. A major recommendation of both of these groups was to establish a centrally-funded technical support group. To address this problem, DoD has instructed the U.S. Army Corps of Engineers Waterways Experiment Station (WES) in Vicksburg, MS, to act as the lead technical support and research and development group for environmental aspects of site remediation modeling, site characterization, and evaluation of remedial technologies. One objective of this modeling component of the DoD environmental quality program is to develop a computational framework that will allow optimal design of remedial efforts. Models developed should be able to address the potential for successful remediation based on site geology, lithology, hydrology, geochemistry, and natural heterogeneities. The modeling component of this program has seven major objectives:

- $\quad$ Evaluate existing remediation technologies.

- Build a new computational framework to address all aspects of site remediation: this framework is known as the Groundwater Modeling System (GMS).

- Investigate the role of natural processes on contaminant fate and transport: emphasis is placed on metals and explosives by the Army, and the Air Force is studying subsurface transport of fuels and solvents.

- Investigate remedial processes: emphasis is placed on increased understanding of transport for remedial additives (e.g., nutrient delivery and bio-fouling), and the role of electrokinetics and electrical heating on remediation.

- Build new tools to conceptualize hydrogeological site characterization. The tools will include methods for using hard and soft data for site conceptualization.

- Optimal application of remediation technologies based on modeling from first principles.

- Provide technology assistance, training, and maintenance. A National Academy of Sciences study recommended that the Army develop an in-house capability to provide technical support in the operation and use of groundwater models. WES has been selected to provide this service. For all codes supported, WES will train Army staff in the use of the codes or act on a consulting basis to address all remediation problems.

One major modeling program geared towards improvernent of subsurface fate and transport modeling is in the Strategic Environmental Research and Development Program (SERDP). The objective of this program is to improve remediation efforts through development of predictive and interpretive engineering tools that address the role of natural variability in influencing transport. The SERDP program is administered by DoD and involves DOE and EPA. The expected level of funding under this program to address the simulation of subsurface transport over the entire range of contamination problems is approximately $\$ 20$ million over five years. The funding will support experimental and computational programs. 
Another major initiative sponsored by DoD is the Groundwater Modeling System (GMS). The GMS is an ongoing multi-year research effort under the direction of WES with support from SERDP. One objective of the initiative is to develop a user environment where existing groundwater models can be integrated and used efficiently. The GMS is designed as a comprehensive graphical user environment for numerical modeling of groundwater flow and transport. Graphical tools are provided for site characterization, model conceptualization, mesh generation, geostatistics, and post-processing of modeling results. The first version of this system has been released and supplies a complete interface for models 3DFEMWATER, 3DLEWASTE, and MODFLOW. Other models will be supported in future versions.

\subsubsection{Department of Energy}

The Department of Energy (DOE) has a number of programs devoted to obtaining information for subsurface fate and transport modeling. Major program areas include the Subsurface Science Program, the Groundwater Modeling Initiative Grand Challenge, and Environmental Management programs.

The DOE Office of Energy research supports the Subsurface Science Program, which covers a wide range of research topics related to obtaining a mechanistic understanding of the physical, chemical, and biological processes that influence contaminant fate and transport. Many of the projects in this program contain substantial experimental procedures. The experimental data are used to develop improved process models. In addition to the experimental programs, a number of programs focus on fundamental research to improve models for contaminant fate and transport. For example, projects on improved modeling of bacterial (biocolloid) transport and reactive solute transport are currently supported.

The DOE Office of Energy Research supports the Groundwater Modeling Initiative, a substantial program on advanced computational techniques in groundwater flow and transport for environmental modeling and remediation. This program is a multi-institutional effort that includes universities such as Rice, Texas A\&M, Wyoming, South Carolina, and Stony Brook, as well as Oak Ridge, Savannah River, and Brookhaven National Laboratories. The objective of this program is to develop multi-phase, multi-component flow and transport models with capabilities to accommodate biodegradation, radionuclide decay, fracture flow, front-tracking, geochemistry, and solute and colloid/microbe transport. This will substantially advance the state-of-the-art in groundwater flow and transport modeling. Issues addressed in this program include restructuring existing codes to fully utilize the capabilities of parallel processing machines, improved numerical methods to handle the larger problem sizes, stochastic parameter estimation, and improved visualization techniques.

Environmental restoration programs support a range of modeling programs. Application of models for remedial investigation/feasibility studies and performance assessments have been conducted at hundreds of sites. These efforts are focused on applying existing models and not on model development, and therefore, will not be discussed further in this report. 
Review of these model applications and their successes and failures is useful in determining areas requiring improvement.

In addition to model applications, environmental restoration programs support a number of projects focused on improving DOE's capabilities in fate and transport modeling. These include projects in multi-phase, multi-component flow and transport, decision support systems, multi-component solute transport, stochastic transport, optimization of data collection, bioremediation/biodegradation, colloid transport, microbial transport and electrokinetic enhanced transport.

\subsubsection{Environmental Protection Agency}

The Environmental Protection Agency (EPA) has a substantial interest in subsurface contaminant fate and transport modeling. As the regulatory agency for Superfund sites, it maintains substantial programs on modeling all release pathways, i.e., surface water, groundwater, and atmospheric. An agency-wide task force has examined the management of all modeling efforts pertinent to EPA's mission. The task force recommended that a permanent group be established within EPA headquarters to provide direction in coordinating the development models. The task force also cited the need for increased training and support on the use of models. EPA has taken the lead role on an Interagency Environmental Pathway Modeling Working Group which has the objective of promoting the more appropriate and consistent use of mathematical environmental models in the remediation and restoration of radioactively contaminated sites. Other agencies involved in this program are the DOE Office of Environmental Management and the NRC Office of Nuclear Material Safety and Safeguards.

EPA has developed an expert system to assist the selection of the applicable computer code from a database of groundwater, surface water, and atmospheric fate and transport codes. The Integrated Models Evaluation System (IMES) was developed to assist in the selection and evaluation of exposure assessment models and to provide model verification and uncertainty information on various models in various environmental media. The Exposure Models Library contains over 90 different public domain fate and transport models, including the source code, documentation, and test problems. The IMES and associated databases are periodically updated to include new models.

The EPA supports the development and use of Decision Support Tools and recently (EPA, 1994) sponsored a workshop on this topic. The use of decision support tools in solving environmental problems is recent and their acceptance and use has not been widespread.

EPA sponsors two laboratories that are heavily involved with environmental fate and transport modeling: the R.S. Kerr Environmental Research Laboratory, and the Environmental Research Laboratory at Athens, Georgia.

The R.S. Kerr Environmental Research Laboratory (RSKERL) is one of 15 EPA research facilities. Since 1979, RSKERL has been designated as EPA's center for groundwater 
research. Their primary focus is to enhance the understanding, modeling, and application of basic principles involved in the physical, chemical, and biological processes that control contaminant transport and transformation in the subsurface. RSKERL has six major areas of emphasis: site characterization, contaminant transport and transformation, subsurface remediation, underground injection control, wellhead protection, and mathematical modeling.

RSKERL supports over 50 research projects. In addition, it is a Superfund technology support center. The RSKERL technology support program operates the Center for Subsurface Modeling Support (CSMoS), the Subsurface Remediation Information Center (SRIC), and the Groundwater Remediation Technologies Analysis Center (GWRTRAC). CSMoS provides direct technical support to the EPA and state decision-makers on the use and application of computer software for groundwater flow and transport problems. In addition, CSMoS manages, distributes, and supports the groundwater and vadose zone models and databases resulting from research at RSKERL. SRIC is a database designed to provide site specific information at waste sites throughout the United States. GWRTRAC is a multi-partner undertaking focused on obtaining a knowledge base of the status of ongoing in-situ groundwater remediation technology development and demonstration efforts. The major emphasis of GWRTRAC is on the evaluation of efforts to remediate subsurface contamination of hazardous waste sites.

The Environmental Research Laboratory in Athens, Georgia, as part of its mission, conducts and supports research in the areas of predictive exposure assessment, ecological risk assessment and risk management, and maintains a Center for Exposure Assessment Modeling (CEAM). The objectives of the predictive exposure assessment work are to establish the kinetics of abiotic and microbial degradation of hazardous chemicals in the environment, characterize and test techniques to enhance these processes to achieve bioremediation of contaminated soils and sediments, develop computerized mathematical models, with appropriate expert systems to predict environmental fate and effects of chemicals, predict the multimedia transport and transformation of pollutants, and develop methodologies for estimating uncertainty in model predictions.

The objectives of the predictive ecological risk assessment and risk management programs that are relevant to subsurface fate and transport modeling are to develop multi-level risk assessment frameworks, methodologies and decision support systems for aquatic environments and to develop quantitative uncertainty analysis methods for assessment and reduction of ecological risk factors.

The objective of the Center for Exposure Assessment Modeling is to distribute developed and supported models to the technical community. The Center provides technical support to EPA and state agencies in environmental risk-based decisions concerning remediation and pollution prevention strategies for the protection of surface water, soil, groundwater, and air. 


\subsubsection{Nuclear Regulatory Commission}

The Nuclear Regulatory Commission (NRC) is the regulatory agency for radioactive waste disposal. It supports modeling for release and transport of contaminants from low-level and high-level radioactive waste disposal facilities. For low-level wastes, the NRC has spent the majority of its effort in developing a performance assessment methodology and supporting models. These models are typically general in nature and are intended to be used to provide reasonable assurance that regulatory performance criteria can be met. They are not intended to provide best estimates of the fate and transport of radioactive contaminants. NRC has supported model development in concrete barrier degradation, waste form and container performance, and unsaturated/saturated zone transport of radioactive solutes. More detailed process model development has been funded to provide support in data selection for the performance assessment models. This work includes stochastic flow and transport modeling and coupled geochemical transport modeling. For high-level waste disposal, modeling efforts have examined the role of fracture flow on contaminant transport as well as non-isothermal flows in fractured porous media.

\subsubsection{National Science Foundation}

The National Science Foundation (NSF) sponsors a number of university programs that span a wide range of areas important to subsurface fate and transport modeling. These areas include multi-phase, multi-component transport, stochastic transport, solute transport, improved numerical techniques, decision support systems, and optimal data collection. Total support for model development work is between $\$ 2$ and 3 million per year.

\subsubsection{United States Geological Survey}

The United States Geological Survey (USGS) conducts a substantial program in contaminant fate and transport modeling. USGS has major interests in multi-phase, multi-component transport modeling, solute transport modeling, fracture flow and transport modeling, and stochastic flow modeling. The USGS is actively involved in modeling contaminated sites throughout the United States. They have simulated the flow of NAPLs, gaseous contaminants, fractured flow of radioactive gases, and fracture flow of solutes. Often, USGS projects include a significant data collection component that supports model development. 


\section{ISSUES IN MODELING: RESEARCH AND DEVELOPMENT NEEDS}

This section presents a number of modeling issues that require further development and is divided into three sections. The first section presents needs related to improved modeling of the physical, chemical, and biological processes relevant to subsurface fate and transport. The numerical solution techniques needed to incorporate these improved mechanistic models are also discussed. The second section deals with the integration of several process models into computer codes and handling the large amounts of data and output involved. The third section discusses requirements for the coordination and management of model development and applications.

\subsection{Improved Process and Numerical Modeling}

As shown in Chapter 4, there are a number of areas related to improved modeling of subsurface flow and transport that are receiving attention. However, much remains to be done to improve the predictive capabilities of models. The subsurface system is so complex . that a complete understanding is not possible. It is unlikely that any amount of effort will completely resolve all the issues related to fate and transport. This allows an open-ended set of options for future action. At some point, a decision must be made as to the adequacy of models. This decision will be based on the intended use of a model, the degree of confidence that can be placed in it, and the impacts that inadequate modeling has on other processes such as regulatory compliance, risks, and costs.

Any model is only as good as the data that supports it. Fate and transport model development requires supporting laboratory-scale experimental programs. The complexity of the subsurface system, the uniqueness of the fate and transport problem (i.e., the mixture of contaminants found in plumes does not occur naturally), and the use of new remediation technologies necessitate experimental data for hypothesis testing and evaluation of the applicability of models. Ideally, model development and experimental programs run concurrently. In addition, field-scale experimental data will be needed to provide information on natural systems. Therefore, model developers need to interact closely with people experienced in collection and interpretation of field and laboratory data.

With these caveats in place, the following areas require better process understanding and modeling: 
- Coupled fate and transport (biochemical and geochemical reactions)

- $\quad$ Multi-component, multi-species transport

- $\quad$ Non-isothermal, multi-phase transport modeling

- Natural variabilities (stochastic modeling)

- Fracture flow

- Interactions of remedial measures with transport parameters and mechanisms

- Conceptual understanding of the role of subsurface heterogeneities on remediation

Improvements to the numerical modeling techniques are necessary to fully utilize the capabilities of parallel processor machines. In addition, the use of parallel processors allows larger problems to be solved. The larger problem sizes require more efficient numerical solution algorithms. Improved numerical techniques such as adaptive grid refinement are also needed to minimize numerical dispersion when tracking steep concentration fronts. A final area that should receive investigation is numerical techniques such as neural network algorithms that will solve more complex problems on relatively small machines.

\subsubsection{Coupled Fate and Transport}

Contaminants in subsurface systems participate in chemical reactions that can alter the chemical form and, therefore, transport rate of the contaminant. These reactions include biodegradation reactions that can be viewed as chemical processes. In general, biodegradation refers to chemical changes in the solute or solid due to microbial action. Possible reaction types include sorption onto the solids in the porous media, precipitation, dissolution, complexation, and volatilization. These reactions can be kinetically controlled if the reaction rate is slow enough that equilibrium is not reached. For solutes, the rates and types of reactions that occur depend on the local solution chemistry such as Eh and $\mathrm{Ph}$, concentration of all other species, temperature, and the type of minerals and solids that are present. The large number of potential reactions leads to substantial data requirements, including reaction rate and equilibrium constants. In addition, the reaction equations are often non-linear. These conditions make multi-species fate and transport modeling a challenging computational task.

Organic non-aqueous phase chemistry is more complicated and less understood than solution chemistry. Biodegradation reactions frequently have an important effect on the speciation and concentration of many organic compounds. Often, the biodegradation reactions are kinetically controlled and the rate constants are not well known. In addition, volatilization can occur and some organic compounds, such as TCE and PCE, frequently exist in the vapor phase.

Many researchers realize that chemical reactions and geochemical interactions provide a critical control of the fate and transport of many contaminants. However, chemical controls are modeled using a few global system parameters such as solubility limits or equilibrium distribution coefficients. Improvements to these models exist with the resulting models known as coupled reactive transport models. 
Modeling of coupled reactive transport is in its infancy. In coupled transport models, the migration of the contaminants is calculated simultaneously with chemical reactions that influence the chemical form in which the contaminant exists and therefore its migration rate. A few models have been developed within the last few years, but application to real-world problems has been scarce, as these models are, for the most part, still in the research phase.

Issues affecting coupled geochemical or biochemical transport models include: excessive computational requirements, excessive or poorly known data requirements, inadequate numerical convergence of the solution, and limited experience with their application to practical problems. In coupled reactive transport models, calculations are performed at each modeled location, for each chemical species being modeled, and at each time step. For a relatively simple problem, this might involve twenty species at one thousand locations, giving 20,000 unknowns per time step. Most reactive transport models assume chemical equilibrium. This assumption removes the requirement to obtain rate constants for all reactions. However, thermodynamic data, particularly equilibrium constants are needed for each reaction. While there are a substantial number of databases containing this information, the databases are not always consistent, nor are they complete.

Many important reactions are not found in the databases. For example, only limited data exist on many of the actinides. The databases tend to focus on major naturally occurring anions and cations that may be substantially different from the contaminants that are often found at relatively low concentrations in nature. In addition, the constraint that the system is at equilibrium is often not met in natural groundwater systems. Many microbial and precipitation reactions are kinetically controlled and equilibrium is an inaccurate approximation. The calculation of the distribution of contaminants within the various species is a highly non-linear problem. This can lead to excessive computational times or numerical convergence problems.

\subsubsection{Multi-Phase Flow and Transport}

In certain situations, it may be necessary to calculate the flow and transport of contaminants in more than one fluid phase. For example, Carbon-14 can exist as a solute and as a component of the gas phase as carbon dioxide or methane. In this example, two-phase flow and transport must be considered. Many organic solutions are either only slightly miscible or immiscible with water, such as gasoline, kerosene, benzene, and TCE. These liquids tend to remain as free separate phases. Therefore, when organics are present, the number of distinct phases can be three or even more if there are several organic phases.

For environmental restoration problems, multi-phase flow models are important for describing movement of organic phases. As a distinct phase, the organic liquids can be less dense (LNAPLs) or more dense (DNAPLs) than the aqueous phase (water). The density plays an important role in determining flow and transport. For LNAPLs, as they reach the saturated zone, or water table, they tend to flow on top of the water table. LNAPLs include gasoline, jet fuel oil, and oil. For DNAPLs, they, tend to sink through the groundwater until an impermeable geologic layer is reached. At this point, DNAPLs may flow along the 
topography of the geologic layer, which may be different than the direction of the groundwater flow. DNAPLs include TCE, PCE and $\mathrm{CCl}_{4}$. In the field, DNAPL flow depends on their concentration and geologic heterogeneities. DNAPLs often form ganglia and pools, and exhibit significant fingering phenomena.

There are three major types of conceptual models to describe flow of NAPLs. The first assumes a sharp interface between the aqueous and NAPL phases. Each phase is treated independently and the gas phase is assumed to be at constant pressure with no gas phase flow. The sharp interface approximation models the system as being dry or containing one fluid phase at a given location. The second conceptual model treats each phase as being continuous and independent, such that no mass transfer exists between phases, but functional relationships that describe the permeability as a function of the degree of saturation of all phases are used. These relationships are site-specific, as they depend upon the properties of each fluid and the subsurface materials. The third conceptual model incorporates interphase partitioning of organics.

In general, NAPL flow depends on the effects of fluid compressibility, gravity and formation geometry, viscosity, phase composition, interphase mass transfer, capillarity, chemical interactions, sorption, diffusion, and dispersion. Although a theoretical framework exists for incorporating these processes in a model to predict multi-phase transport, natural heterogeneities, insufficient data, and inadequate understanding of the physical and chemical processes that control NAPL movement prevent accurate prediction of their migration. For example, the degree of sorption of organics depends or, among other things, the degree of saturation of the aqueous phase. Typically, organic sorption is greater at lower levels of water saturation.

Essentially all of the current models assume that each phase is continuous. At low organic fluid saturations, the organic phase may exist as isolated globules surrounded by water. The current models would assume that these isolated organic globules are immobile. However, migration of these globules can occur, resulting in a process called "blob flow." This process is seen in tertiary oil recovery where attempts are made to mobilize the "blobs" using injected surfactants and gases. For the most part, existing models and computer codes do not treat "blob flow" satisfactorily.

Current understanding does not permit an accurate analysis of fate and transport modeling of NAPLs. Even after substantial characterization efforts have been undertaken, it is not always possible to define the location and amount of NAPL contamination. Data for permeability, sorption, dispersion, and other transport properties as a function of saturation are not well known. In addition, mass transfer between the aqueous, gas, and NAPL phases is not well characterized. Finally, the kinetics of biodegradation reactions are also not wellknown. 


\subsubsection{Heterogeneities and Stochastic Fate and Transport Modeling}

Natural systems are physically, chemically, and biologically heterogeneous. These heterogeneities often exhibit substantial impacts on contaminant fate and transport. The impacts of heterogeneities are largely not quantified, which produces significant uncertainty in the selection and application of remediation technologies. Conceptualization of the natural system to include these heterogeneities is needed. Stochastic fate and transport modeling is one approach used to quantify the uncertainty in modeling parameters.

In stochastic models, it is assumed that the spatial distribution of transport properties can not be determined in detail, but the statistical characteristics of the variability in properties can be evaluated with site characterization. Using the statistical information, the stochastic models allow the uncertainties in the data to be propagated through the models to estimate the uncertainties in the model predictions. Two major stochastic approaches are used: the equivalent homogeneous approach and the heterogeneous approach. In the equivalent homogeneous approach, the site is approximated as a homogeneous effective media in which the transport parameters are estimated via statistical analysis of the data. This greatly simplifies the models and allows deterministic models to predict the mean behavior of the system. The heterogeneous approach treats the subsurface environment as a heterogeneous medium and randomly assigns parameter values to different spatial locations consistent with the statistical distribution of measured data. Techniques such as geostatistics, Monte Carlo simulation, and conditional Monte Carlo simulation are used. These methodologies predict a distribution of outcomes with their probability of occurrence.

Substantial efforts are being focused on addressing the role of heterogeneities in transport through stochastic modeling. Limitations in stochastic modeling include obtaining enough data to determine statistically meaningful distributions of parameters and excessive computing requirements. In addition, as with all flow and transport models, a universally accepted criteria for validation of stochastic models does not exist. Stochastic modeling has focused more on variability in hydraulic conductivity, which alters the fluid flow rate and distribution, than on contaminant transport parameters. Increased efforts should be made to extend the models to spatially variable transport parameters. Also, the effective homogeneous approach to stochastic modeling has not been successful in dry soils.

An area that requires guidance on the proper utilization of models involves the use of probabilistic models, which provide a distribution of possible outcomes as compared to deterministic models, which predict a single outcome. Currently, there is some controversy over the use of probabilistic modeling rather than deterministic modeling.

In the deterministic approach, parameter values are selected, the model is exercised, and a single realization is predicted. This simulation represents one possible outcome of system performance. If the parameters have been properly selected, this realization may provide an upper bound on the performance measure. However, contaminant fate and transport is a complicated process that inherently contains variability in parameters and therefore in system performance. Often, when using the deterministic approach, a sensitivity analysis is 
performed to address this variability. This analysis varies parameters within their expected range, determines the parameters that have the greatest influence on the performance measure, and determines the range of outcomes. The effective homogeneous approach with stochastically determined parameters is a deterministic approach.

The natural variability of parameters and the uncertainty as to the best choice of parameters lead many to believe that a probabilistic approach should be used to assess fate and transport. A probabilistic approach has been recommended by EPA for assessing contaminant fate and transport resulting from high-level waste disposal and it is recommended, but not required, by the NRC when assessing the outcome of low-level waste disposal [Campbell, 1994].

The probabilistic approach provides a systematic method for examining the range of potential outcomes within the system. However, interpretation of the results is often difficuit. Many regulations are written in a deterministic fashion, such as the groundwater concentration must be less than $5 \mathrm{ppb}$. When using the probabilistic approach, a range of possible concentrations are predicted with the associated occurrence probabilities. The problem arises in interpreting the probabilistic output against a deterministic standard. For example, if the probabilistic model predicts that there is one chance in a hundred that the contaminant concentration exceeds the standard, it is not clear if the modeled alternative is acceptable.

\subsubsection{Fracture Flow}

The process of fracture flow is not well understood or modeled at this time. In fracture flow, small discontinuities like cracks form a connected network. Flow and transport can occur through both the fractures and the porous matrix.

Several different approaches are used to model fracture flow of liquid solutions. These include an equivalent porous medium approach in which the conductivity of the fractures and porous media are weighted to give an effective conductivity. This approach may be useful in predicting average flow rates but is not accurate for transport. The second approach is to model the system as a dual porosity medium. In this approach, the fractures and the porous matrix are assigned unique transport parameters. The most detailed models simulate an interconnected discrete fracture network. The choice of an appropriate model depends on the site characteristics. As with porous media transport modeling, either a deterministic or a stochastic approach can be used.

Some believe that the major problem in modeling fracture flow is poor characterization. They feel that if the site were perfectly characterized with respect to the location, orientation, flow characteristics, and size of all fractures, current models would adequately predict contaminant transport in the fractures. Others believe that more work needs to be done to understand the mechanisms of fracture flow. Issues involve the impacts on flow and transport due to variable aperture size, surface roughness, alterations in fracture permeability due to dissolution-precipitation reactions, improved model representations of the fracture system, and determining fate and transport parameters of NAPLs. In any event, perfect characterization will never be obtained and a method to handle uncertainties in the geometry 
of the fracture network will be required. Due to the variability in fracture flow systems, modeling must be site-specific and performed in conjunction with site characterization.

Fractures can also provide a rapid transport pathway for gas phase contaminants. Flow induced by barometric pressure variations over fractured media have shown transport rates of a few meters per day [Cameron, 1987; Nilson, 1992]. Little data or experience exist on the transport of gas phase VOCs in fractured systems.

\subsubsection{Numerical Solution Techniques}

An area of rapid growth and potentially significant improvements over current modeling capabilities stems from the use of parallel processing machines and distributed computing. Currently, efforts in this area are focused on using currently existing techniques while expanding the level of detail in the analysis, i.e., calculating problems at millions of spatial locations in transient problems. The enhanced spatial resolution lends itself naturally to stochastic modeling, which simulates the variability of the transport parameters. In addition, parallel processing is ideally suited for modeling geochemical or microbial reactions at each spatial location. This can help overcome the computational burden imposed when using these types of models.

The parallel processing methods naturally require more effort in improving the numerical methods and efficient use of the processors. Most numerical techniques require more than a linear increase in execution time with problem size. Therefore, the larger problem sizes that are possible to compute on parallel machines require improvements to the standard numerical techniques. In addition, research is required to optimize the simultaneous use of the processors.

A final issue with modeling using parallel processing machines is the restricted access and the limited number of technically qualified users. Currently, access to the parallel processing machines is limited to universities, national laboratories, and large companies. Parallel processing work is at the research stage and the professional background of most people that work with parallel processing machines is either applied mathematics or computer science. In contrast, a large fraction of fate and transport modeling work is performed by relatively small consulting firms using microcomputer based technology. The professional backgrounds of the people most commonly performing these modeling efforts are in hydrology, geology, geochemistry, and chemistry. If state-of-the-art models are developed on parallel processing machines, their use will initially be available to a select few. Substantial technology transfer and training will be needed to rapidly employ the advances in parallel computing.

Improvements to numerical solution techniques may be needed when tracking the movement of sharp interfaces between phases. Current techniques often introduce numerical dispersion. which smears the interface. Adaptive grid refinement techniques show promise in this area and should be further supported. 
A final area that shows promise in solving large complex problems with minimal computer requirements involves the application of neural network algorithms. This innovative approach is conceptually different than solution of the advection-dispersion equation, and may lead to reduced computational requirements over standard techniques. This technique defines the system through an interconnected set of processing units. Each unit receives multiple normalized input signals and generates a single output. The output of each unit typically forms input to another processing unit. The processing units are "trained" through the use of solutions to more complicated problems. For example, the network could be trained to simulate the advection-dispersion equation by incorporating information from the solution into the weighing functions of the processing units. This would permit more rapid, less expensive solution of the problem than by using a detailed numerical solution.

\subsubsection{Influence of Remediation Efforts on Fate and Transport}

Theoretical and computational work to examine the role of remediation efforts, and their effects on fate and transport are being minimally investigated. In the near-term, fate and transport modeling can be used to optimally design rernediation solutions. In the long-term, remediation efforts may alter the local hydrology, geochemistry, and microbiology, influencing transport characteristics.

Near-term modeling issues include the transport of additives such as surfactants, bacteria, air, steam, and others from their injection point to the contamination zone, the interaction of the additives with the contaminants, and the alteration of the contaminant transport properties due to remediation process. Modeling issues pertaining to the long-term effects of remedial actions are typically not addressed. For example, once the remedial action is finished, questions pertaining to how the local flow, chemistry, and microbiology were changed and what impacts these changes will have on subsequent transport, are not considered.

\subsection{Improved Information Processing}

A major role for the use of a computer model is to provide information useful for decisionmaking. As such, the output of these models should be presented with a format that is clear and easy to interpret. As computers become more powerful, fate and transport models become more detailed and complex, causing data requirements and use to increase. When the process evolves, improved techniques will be needed to handle the amount of information used to simulate subsurface fate and transport. Areas for improvement include input and output processing, e.g., visualization, geostatistics and GIS technologies, data standardization and transfer between different platforms and systems, and data reduction and fusion.

Input processing could be improved by taking advantage of recent progress in computer systems. The graphic environments available on PC and UNIX based systems should be utilized to ease the burden of data input. These input processors should also have automatic computational mesh generation with a graphic display and editing capabilities of the mesh. Graphical display of initial and boundary conditions, and any other tabular or functional input, such as hydraulic conductivity as a function of moisture content should be provided. 
The improved processors will allow modelers a better control over problem definition and will minimize errors associated with building complex simulation models.

As computer models become more detailed and have more demanding input requirements, the need for improved data handling increases. The input processors should relieve the code users from the need to learn the detailed structure and format required by the computer code. Advances are being made in this area. The Groundwater Modeling System (GMS), for example, and other decision support systems have substantial input processing capabilities. However, many of the models in widespread use do not address this issue. Historically, limited funding has precluded development of appropriate data and output processors along with the models. This has often resulted in difficulties in introducing improved models to the users in a timely fashion.

Visualization techniques exist which permit the user to obtain practically any view of the data that is desired. These techniques include the capability to produce 3-D representations, isosurface plots, vector plots, perspective rotation, and time evolution of parameters and solution distributions. The physical intricacy of the subsurface system, i.e. complex geologic geometry, and of the flow patterns make visualization tools an extremely important instrument for interpretation and presentation of model predictions. However, their integration into most models is non-existent or limited. Ideally, the transition from computer output to a graphical image would be seamless, and would not require the code user to reformat data. Efforts in this area are being made in the GMS and the DOE Groundwater Modeling Initiative.

The increased data collection through site characterization and development of more detailed models such as stochastic flow and transport, coupled geochemical transport, coupled microbial transport and fracture flow models, have increased data handling needs. Techniques need to be developed to interpret data from different sources in a coherent manner, such as in data fusion, and for manipulating the raw data to obtain model input parameters for the codes, as in geostatistical mapping and generation of stochastic distribution of parameters. The increased data collection also highlights the need for developing databases that are portable between different platforms, and data standardization. Databases of physical, chemical, and biological parameters could be useful, particularly if the data are generic, such as chemical and biological constants for reaction rates and thermodynamic equilibrium values.

\subsection{Coordination of Model Development and Application}

Subsurface fate and transport modeling will require a wide range of models to address all potential issues. Areas to be covered include biodegradation and biotransformation, geochemistry, multi-phase systems, fracture flow, colloid transport, and microbial transport. It is not practical, nor desirable, to have a single model cover all possible physical, chemical, and biological situations. A recent EPA study on subsurface fate and transport modeling listed over 400 separate models covering the different processes [van der Heijde, 1993]. 
Given the large number of Federal agencies with substantial fate and transport modeling programs, the large number of modeling programs under development identified in this study, and the many existing models, coordination and oversight is clearly needed. This coordination would include:

- $\quad$ Minimizing duplication of effort;

- $\quad$ Facilitating the integration of knowledge between different programs;

- Providing technology assistance and support on model verification and confidence building;

- $\quad$ Providing technology assistance and support on acceptability of models and their application;

- Providing technology assistance and support on how to handle uncertainty in modeling predictions; and

- $\quad$ Facilitating technical transfer of model development.

In the past ten years, development and application of models to provide information for decision making has seen a rapid increase. For the most part, models have been developed on an as-needed basis without planning for application of the models beyond the problem for which they were developed. This promoted duplication of effort and de-emphasized the need for making models accessible and adaptable to other applications.

Subsurface contamination is a major issue for EPA, DoD, USGS, DOE, and USDA. The need for integration between the various agencies is important. Even within each organization, several offices have substantial fate and transport modeling efforts. In the case of DOE, these include groups within the Office of Environmental Management, the Office of Energy Research Subsurface Science Program, and the Office of Energy Research Grand Computational Challenge. Communication between these groups should be encouraged to improve integration of efforts. This report is intended to contribute to this process.

The need for communication also extends between government agencies and private industry. Significant remediation activities are needed in the United States and worldwide. If U.S. industry is to effectively compete in the remediation marketplace, a substantial technical transfer between government-sponsored programs and industry is needed. This would include training as well as transfer of experimental data and computer models. In addition, industry is currently performing many fate and transport studies. Their insight and knowledge into the problems associated with model application would be valuable in defining model and data needs.

As models are developed, they undergo a significant amount of verification testing to demonstrate that the model is capable of performing as intended. Model verification can be obtained through comparison of model predictions with known analytical solutions and intercode comparisons. Guidance for appropriate field scale problems to be used for verification is needed. While substantial efforts have been made to develop new models, little effort has been made to find sites that can serve as tests for the models. This is especially true for areas that have only recently been addressed, such as coupled geochemical transport, 
microbial transport, and multi-phase flow and transport. In addition, criteria for testing of stochastic models using well characterized field studies does not exist.

Building confidence in a model by demonstrating that the model can fairly accurately predict the response of the natural system to real-world problems is difficult to achieve. The intricacy of the subsurface system, the inadequate knowledge of the system, and the natural variability make the task demanding. The best approach to build confidence in model capabilities is to compare the model against carefully designed and controlled field scale tests. Even with these better-defined systems, matching model predictions to experimental results can usually only be achieved through calibration of the models. Many models have been successfully calibrated to a particular problem and site. After calibration, the models can reproduce the experimentally measured data. However, the predictive powers of the model are still not demonstrated.

In a 1984 conference of geochemists involved with high-level radioactive waste management issues, the consensus was that addressing all the questions related to high-level waste geochemistry would require at least 15 years of funding at a level equivalent to that of the space program [Jacobs, 1985]. Similar statements, though perhaps as drastic, could be made for understanding fracture flow, microbial transport, and colloid-facilitated transport.

The preceding example illustrates two important issues with respect to management of models. First, provisions must be made to deal with uncertainty in model predictions. The knowledge base will always be incomplete and therefore, modeling will never be able to provide an absolute guarantee. Second, provisions must be made to define when the level of information is sufficient to justify the conclusions. This is a problem-specific, site-specific issue and not an easy one to address.

Technical transfer of the knowledge and models developed under government funding should be increased. Technical transfer will facilitate the proper use of the codes and help insure that the best tools are available for environmental restoration and waste management efforts. Technical transfer would include better documentation of codes, training on the use of codes, and technical support for code applications. A recent study by EPA found that over $50 \%$ of the people who use modeling results have little or no experience with models [EPA, 1993]. To address some of these problems, the EPA established the Center for Subsurface Modeling Support. However, in the DOE community, technical support is provided on an ad-hoc basis. Some code developers have conducted training courses and many codes are available from the International Groundwater Modeling Center and the DOE sponsored Energy Science and Technology Software Center at Oak Ridge National Laboratory. However, these software centers do not supply sufficient technical support on the use of models.

\subsection{Summary and Recommendations}

Table 5.1 lists the major issues identified in this section. It is divided in three sections as discussed in the report: improved process and numerical modeling, improved information processing, and coordination and oversight of modeling initiatives. Based on these general 
Table 5.1 Summary of Improvement Areas in Fate and Transport Modeling

\section{PROCESS UNDERSTANDING AND NUMERICAL MODELING}

\section{Process Understanding and Modeling}

Coupled multi-species, multi-component fate and transport

Non-isothermal multi-phase transport

Stochastic modeling

Fracture flow

Numerical Modeling

Parallel processing algorithms

Efficient discretization techniques (adaptive grid)

Alternative approaches to mathematical modeling (neural networks)

\section{INFORMATION PROCESSING}

Visualization Techniques for input and output processing

Data reduction (data fusion)

Geostatistical mapping

Data standardization to facilitate transfer between different hardware and software platforms

Geographical information systems

\section{COORDINATION OF MODEL IDEVELOPMENT AND APPLICATION}

Minimization of duplication of effort

Integration of knowledge between different programs

Guidance on model acceptability

Guidance on model verification and confidence building

Coordination of training and technical transfer of models

areas, specific recommendations are discussed in this section.

Improved process and numerical modeling are needed in the areas listed in Table 5.1 to provide better tools to address the complex issues pertaining to subsurface fate and transport. The objective of developing better tools is to permit better decisions pertaining to remediation issues to be made. Chemical contamination with mixtures of contaminants has been shown [Riley, 1992] to be a widespread problem. Therefore, more attention is needed to increase understanding of the impact of chemical and biological reactions on transport.

These effects are poorly understood in many natural systems and can greatly affect long-term 
estimates of transport. Model development programs will need to interact with experimental programs and should be focused on addressing the most common and important problems.

In addition, improved process models are needed to assist in obtaining improved estimates of the fate and transport of NAPLs, the effect of heterogeneities on transport, and the role of fractures on flow and transport. An accurate analysis of fate and transport modeling in each of these areas is not always possible at this time. The movement of NAPLs often occurs as isolated blobs. The process of blob formation and transport is not well understood. Heterogeneities in transport parameters and chemical reactivity can play a major role in defining the flow paths and therefore, transport rates of contaminants. The details of how to conceptualize and model these heterogeneities require further work. Stochastic modeling is one approach being used to model heterogeneities. Fracture flow and transport over field scales is often difficult to model accurately. Several different approaches are often used to assess potential outcomes when fracture flow occurs. More work is needed to improve the understanding of fracture flow. In each of these areas, model development in the absence of experimental data will most likely be unsuccessful. Substantial experimental work will be needed in conjunction with model development.

As models become more complex and require increasing degrees of computational sophistication, improvements to numerical techniques and innovative approaches to solving the problems will be necessary. Improvements will be needed to handle the large amounts of data and large computational problem size, including improved numerical techniques for solving large systems of equations. In addition, innovative approaches such as adaptive grid refinement will be needed to handle large modeled domains where changes are occurring rapidly over localized regions. For example, if disposal and remediation involves large amounts of cements in the source region, the local chemistry including $\mathrm{pH}$ and major ions will differ drastically from the natural system. Geochemical effects on transport may be changing rapidly in the source region, while remaining relatively constant in other regions.

Improved information processing will help to reduce model implementation error and facilitate the proper use of models. Information processing will include improved input/output routines for computer models. In particular, input processing techniques that assist in the specification of the geometry and heterogeneity in the subsurface system are needed. Better information processing is also needed to take both the hard and soft data used to characterize a site and incorporate both into the system conceptual model. Integration of data from various sources will become increasingly important. Improved data visualization techniques are needed to assist in the interpretation of model predictions. Several data visualization techniques exist, but they are not integrated with fate and transport models.

Oversight of model development and application is the area in which immediate action can be taken to improve use of existing models and focus development on model improvements. Modeling of subsurface systems requires expertise in a wide range of disciplines, e.g., geology, hydrology, geochemistry, microbiology, numerical analysis, and statistics (uncertainty analysis) and mathematics. Each of these disciplines will have a limited perspective of the overall objective. Therefore, oversight is necessary to integrate the 
different disciplines, set priorities, and effectively facilitate the transfer of technology to the users and enhance proper application of models.

Model applications are focused on providing the decision-maker with additional information to support the decision, including meeting regulatory limits, extent of required remediation, and which remediation technologies are to be used. Oversight will help ensure that an integrated approach that accounts for the needs of the user, such as contaminated site operators, the connection between model application and data collection, and the proper application of the model are all incorporated into the information gathering procedure. Development and use of decision support systems can be an effective approach to enhance the probability of incorporating all facets of the problem into the decision-making process.

When existing process models are determined to be inadequate, efforts will be needed to address model inadequacies. Oversight will help to prioritize the needs for model development. Model development must be done in conjunction with experimental data collection.

To encourage proper use of models, technical transfer through more thorough training should be supplied. Often, decision makers are not well versed in the intricacies of subsurface fate and transport modeling. Training of decision-makers, contractors involved in modelling, and other stakeholders will improve the implementation and interpretation of models and their end product.

Contaminant fate and transport modeling is a large concern for several Federal agencies. More effective coordination and cooperation between these different agencies will help minimize duplication of effort, help leverage programs such that common areas of interest can be addressed more effectively, and promote the dissemination of experience and knowledge between different groups. Table 5.2 summarizes the recommendations of the preceding section. 
Table 5.2 Recommendations for Improved Model Development and Applications

\section{PROCESS UNDERSTANDING AND NUMERICAL MODELING}

Process Understanding and Modeling

Improve modeling capabilities in the following areas:

- Coupled geochemical transport

- Coupled microbial transport

- Impact of heterogeneities on flow and transport

- $\quad$ Role of fractures on flow and transport

- Multi-phase flow and transport (NAPLs)

\section{Numerical Modeling}

Continue development of advanced numerical techniques (adaptive grids, neural networks, advanced matrix solution techniques, etc.). Integrate these developments into tools useful for decision-making.

\section{INFORMATION PROCESSING}

Continue development of advanced visualization and data integration techniques. These will facilitate proper use of the models and reduce implementation errors. Work towards standardization of data format (GIS, site characterization data, etc.) to facilitate transfer between different platforms.

\section{COORDINATION OF MODEL RESEARCH, DEVELOPMENT AND} APPLICATION

- Pursue an integrated approach to oversight of application and development of fate and transport models.

- Form a working group that oversees application and development of models.

- Improve coordination and collaboration between Federal agencies with substantial involvement in fate and transport modeling.

- Increase technology transfer on the role of models and their applications through training. 



\section{CONCLUSIONS}

A detailed review of ongoing fate and transport model development being funded through U.S. Government agencies has been conducted. The review identified several hundred modeling programs covering the different aspects associated with subsurface fate and transport. Major areas of emphasis include multi-phase flow and transport, stochastic modeling, decision support systems, and multi-component transport. Less emphasis is being placed on improvements of models of biodegradation/bioremediation, fracture flow, microbial transport, pesticide transport, improved numerical solution techniques, and optimal design and data collection.

This review summarized the problems at DOE sites and found that mixed wastes are predominant. This finding indicates that co-contaminant transport will be an important issue for DOE. A major effort is needed to develop improved models of geochemical and microbial effects on contaminant fate and transport in real systems. Model improvement must complement experimental research and data collection. Other major concerns include transport of NAPLs, fracture flow, and the impact of heterogeneities on fate and transport. Each of these areas is receiving some attention. The capability to predict the migration of NAPLs has not advanced to the point where confidence can be placed in the results. Similarly, the role of fractures on controlling transport is not well understood. Further data collection and modeling will be required in both of these areas. The role of heterogeneities on controlling fate and transport has recently been recognized as being crucial for accurate predictions of transport. This area will hopefully receive major support from the DoD Strategic Environmental Research and Development Program (SERDP) and should be followed closely.

As models become more detailed and complex, data requirements and processing demands increase. Therefore, improved techniques will be necessary to handle the amount of information used when simulating subsurface fate and transport. Areas for improvement include input and output processing, visualization techniques, and data transfer between different platforms and systems.

The scope and breadth of subsurface contaminant transport spans many disciplines including hydrology, geology, geochemistry, microbiology, and numerical analysis. While speaking with researchers about fate and transport modeling, all had a clear idea of what was needed in their field, but only a few had any idea about what was needed overall. This highlights the need for a central focus with a clearly defined mission of the role of modeling in environmental restoration efforts. To that end, the following recommendations are made: 
- An integrated approach in coordination and oversight of fate and transport models should be pursued. The oversight should focus on the appropriate use of models and model development needs to obtain answers important to environmental restoration.

- A working group that has an oversight role and directs the emphasis for future work on all fate and transport modeling and experimental data collection that supports modeling should be developed.

- Several Federal agencies have substantial fate and transport modeling programs. Interagency ties should be strengthened to coordinate and leverage modeling work being funded by government agencies.

- Misuse of existing models is a considerable problem. Increased effort in technology transfer is needed to reduce application errors. This would involve training people on the concepts behind as well as the proper use of the models.

Some of these recommendations are being performed to a degree. For example, DOE and EPA are partnering with DoD in the SERDP program on modeling of heterogeneities in subsurface systems.

If relatively simple models with few parameters can provide enough information to make a defensible decision, existing models may be adequate. This approach is commonly used for demonstration of compliance with regulatory limits. In this approach, obtaining reliable data is crucial for providing confidence in model predictions. However, often the physical, chemical, and biological phenomena that control contarninant fate and transport are not well understood and simple models are inadequate. This is particularly true when attempting to use models as a tool for providing support for remedial action decisions. Also, when performing remedial action, decisions pertaining to the volumetric extent of remediation, the placement and number of wells for monitoring, and the remediation treatment will in part be based on fate and transport modeling. A poor understanding of the contaminant migration process may lead to inadequate utilization of resources, such as excessive costs or incomplete remediation. The amount of effort and the degree of sophistication involved in modeling contaminant fate and transport will be determined by the needs of the decision-makers and user community. This highlights the need for effective oversight and management of models. 


\section{REFERENCES}

[Cameron, 1987]

Cameron, C.P., "A Review of Radon Emanation and Mobilization in Minerals and Rocks," WES-MP-GL-87-27, U.S. Army Engineer Waterways Experiment Station, Vicksburg, MS, September, 1987.

[Campbell, 1994]

Campbell, A.C., et. al., "Branch Technical Position for Performance Assessment of LowLevel Radioactive Waste Disposal Facilities," Waste Management '94, Vol. 3, ed. R.G. Post, pp. 1897-1902, 1994.

[DOE, 1994]

U.S. Department of Energy, "Environmental Management, 1994: Progress and Plans of the Environmental Restoration and Waste Management Program," DOE/EM-0119, February, 1994.

[DOE, 1994a]

U.S. Department of Energy, "In-Situ Remediation Integrated Program, Technology Summary," DOE/EM-0134P, February, 1994.

[DOE, 1994 b]

U.S. Department of Energy, "Subsurface Science Program: Program Overview," March, 1994.

[DOE, 1994c]

U.S. Department of Energy, "Innovation Investment Area, Technology Summary," DOE/EM-0146P March, 1994.

[DOE, 1994d]

U.S. Department of Energy, "U.S. Department of Energy Office of Environmental Management Office of Technology Development, FY 1995 Technology Development Needs. Summary," DOE/EM-0147P, March, 1994.

[DOE, 1994e]

U.S. Department of Energy, "Uranium in Soils Integrated Demonstration, Technology Summary," DOE/EM-0148P, March, 1994. 
[DOE, 1994f]

U.S. Department of Energy, "Buried Waste Integrated Demonstration, Technology Summary," DOE/EM-0149P, March, 1994.

[DOE, 1994g]

U.S. Department of Energy, "Characterization, Monitoring, and Sensor Technology Integrated Program (CMST-IP), Technology Summary," DOE/EM-0156T, April, 1994.

[Edson, 1994]

Edson, D.V., "Workshop on Modeling Needs/Support for Radioactive and Mixed Waste Sites: Summaries and Lessons Learned," Seattle, June 30, 1994, JK Research Associates, Inc., 1994.

[EPA, 1992]

U.S. Environmental Protection Agency, "Ground-Water Modeling Compendium: Model Fact Sheets, Descriptions, Applications, and Assessment Framework," EPA Office of Solid Waste and Emergency Response, EPA-500-B-92-006, 1992.

[EPA, 1993]

U.S. Environmental Protection Agency, "Computer Models Used to Support Cleanup Decision-Making at Hazardous and Radioactive Waste Sites," EPA Office of Air and Radiation, EPA-402-R-93-005, 1993.

[EPA, 1993a]

U.S. Environmental Protection Agency, "Environmental Pathway Models -- Ground Water Modeling in Support of Remedial Decision-Making at Sites Contaminated with Radioactive Material," EPA Office of Air and Radiation, EPA-402-R-93-009, 1993.

[EPA, 1993b]

U.S. Environmental Protection Agency, "Environmental Characteristics of EPA, NRC, and DOE Sites Contaminated with Radioactive Substances," EPA Office of Air and Radiation, EPA-402-R-93-011, 1993.

[EPA, 1994]

U.S. Environmental Protection Agency, "Decision Support Toois Workshop, Seattle Washington, June 28-29, 1994.", 1994.

[EPA, 1994a]

U.S. Environmental Protection Agency, "Robert S. Kerr Environmental Research Laboratory, Research Program" EPA/600/K-94/004, June, 1994.

[EPA, 1994b]

U.S. Environmental Protection Agency, "Environmental Research Laboratory - Athens, GA, 1993 Highlights," EPA/600/R-94/092, June, 1994. 
[Jacobs, 1985]

Jacobs, G.K., and S.K. Whatley, "Proceedings of the Conference on Application of Geochemical Models to High-Level Nuclear Waste Repository Assessment Held at Oak Ridge, Tennessee, October, 2-5, 1984," NUREG/CP-0062, 1985.

[Moskowitz, 1992]

Moskowitz, P.D., R. Pardi, M.P. DePhillips, and A.F. Meinhold, "Computer Models Used to Support Cleanup Decision-Making at Hazardous and Radioactive Waste Sites," Risk Analysis, V. 12, No. 4, 1992.

[NERSC, 1994]

National Energy Research Supercomputer Center, "Computing at the Leading Edge Research in the Energy Sciences," UCRL-TB-111084, 1994.

[NRC, 1990]

National Research Council, "Ground Water Models: Scientific and Regulatory Applications," National Academy Press, Washington, D.C., 1990

[Nilson, 1992]

Nilson, R.H., et. al., "Field Measurements of Tracer Gas Transport Induced by Barometric Pumping," Proceedings of the Third International Conference on High Level Radioactive Waste Management, V. 1, pp. 710-716 Las Vegas, NV, 1992.

[Riley, 1992]

Riley, R.G., J.M. Zachara, and F.J. Wobber, "Chemical Contaminants on DOE Lands and Selection of Contaminant Mixtures for Subsurface Science Research," DOE/ER-0547T, 1992.

[van der Heijde, 1993]

van der Heijde, P.K.M., O.A. Elnawawy, "Compilation of Ground-Water Models," EPA/600/R-93/118, May, 1993. 



\section{Appendix $A$ \\ List of Current R\&D Fate and Transport Modeling Initiatives}

Following is a list containing a short descriptive title, performing agency, and funding agency for each funded program that has a significant modeling component.

Title

Barrier Emplacement

Apply models to design experiments for viscous barriers

Subsurface Barrier Design module

Bioremediation/Biodegradation

Decision support

Decision support

Role of bacteria on transport

Optimal design for bioremediation of fuel oil spills

Bioremediation at Rocky Flats and Hanford

Biodegradation of TCE and PCE

Database

Physical and chemical properties of pesticides

Information management system (commercial radioactive waste)

Exposure models library

Decision Support

Role of cover barriers

Environmental Decision Support System (EDSS)

Integrated Model Evaluation System (IMES)

Bioremediation

Pump-and-treat

Bioremediation
Performing

Institution

LLNL

DOE

DoD

MIT

EPA

Rice

ORNL

Rice

Stanford

INEL

\section{ARS}

INEL

USDA

DOE

EPA

EPA

$\begin{array}{ll}\text { LANL } & \text { DOE } \\ \text { SNL } & \text { DOE } \\ \text { EPA } & \text { EPA } \\ \text { Rice } & \text { EPA } \\ \text { Rice } & \text { EPA } \\ \text { MIT } & \text { EPA }\end{array}$


Title

Groundwater quality

Pesticide management

Nitrogen application

Groundwater quality

Surface water quality

Crop management

Evaluation of water quality and data worth

3-D air sparging model for optimum vapor vacuum extraction

Expert systems for salt affected soils

Electrokinetic Enhanced Transport

Modeling electrokinetic transport

Electrokinetically enhanced transport

Electrokinetics design modules

Flow and Transport

Colloid Transport

Role of natural organic matter in colloid transport

Chemistry of organic-radionuclide colloid mixtures

Colloid facilitated transport of pesticides

Fracture Flow

Field scale model application -- 3-D fracture network
Site characterization in fractured rock systems to

improve

Pump-and-treat modeling

Fracture flow and transport

Fracture flow in a multi-layered aquifer

Fracture flow of gases in the unsaturated zone

Fracture flow of Radon at Yucca Mountain

Fracture flow of Radon at Yucca Mountain

\section{Groundwater Management}

Focused recharge area management

Catchment scale - pesticide transport

Management using GIS and expert systems

Uncertainty analysis of groundwater management models

Irrigation systems

Catchment scale water quality

Catchment scale water quality

Catchment scale water quality
Performing

Institution

Iowa State

N.C. State

U. Idaho

Purdue

Purdue

ARS

Stanford

$\mathrm{VPI}^{3}$

ARS

MIT

Lehigh

WES

U. AZ

PNL

Kansas St.

MIT

CRISP

LLNL

USGS

USGS

USGS

CNWRI

SNL

U. Minn

U. Minn

Oklahoma St

Oklahoma St

EPA

USGS

USGS

USGS

NRC

DOE

U. Idaho

Miss. State

NC State

U. Georgia
USDA

USDA

USDA

USDA

USDA

USDA

USDA

USDA 
Title

Catchment scale water quality

Catchment scale water quality

Catchment scale water quality

Catchment scale water quality

Catchment scale water quality

Catchment scale water quality

Optimum water quality using GIS and multi-

component flow

Snow melt run-off modeling

Water quality under pumping conditions

Water quality; root zone transport; improved

input/output

Water quality in salt affected lands

International Programs

Groundwater at Russian sites

Contaminant transport at Russian sites

Microbial Transport

Microbial transport

Percolation modeling

Role of bacterial transport on microbial transport

Microbial transport and biotransformation

Microbial transport

Microbial transport in the vadose zone

Multi-Component Solute

Role of kinetic chemical and biological reactions

3-D hydrogeochemical flow and transport

3-D hydrogeochemical flow and transport/microbial transport

LLW coupled hydrogeochemical flow and transport 2-D

LLW source term analysis

Particle tracking method for hydrogeochemical transport

Multi-Phase, Multi-component

NAPL movement across bedding interfaces

Vapor and solute transport under caps

Role of sorption on multi-phase flow properties

Role of microbial action on NAPL flow
Performing

Institution

U. Florida

Louisiana St

Miss. State

Miss. State

Miss. State

Miss. State

Penn State

ARS

ARS

ARS

ARS

PNL

LLNL

DOE

DOE

PNL

ANL

ORNL

Montana State

INEL

UC- Riverside

DOE

DOE

DOE

DOE

DOE

USDA

U. IL

EPA

Penn State

DOE

Penn State

EPA

BNL

NRC

BNL

NRC

DOE

Oregon State

DOE

SNL

DOE

U. Michigan

DOE

PNL 
Title

Multi-component, multi-phase, solute flow

Validation of approximate multi-phase flow model KOPT

3-D NAPL flow and transport model

3-D multi-phase flow and transport

Screening models for hydrocarbon spills

Grand challenge: Groundwater modeling initiative

NAPL transport in porous media

Hydrocarbon transport in ice/soil systems

Develop, adapt, test models for VOC transport in arid sites

NAPL flow and transport in porous media

3-D NAPL flow in the water table

Multi-phase flow and transport

NAPL flow in heterogeneous porous media

Competitive sorption of hydrocarbons

Multi-phase flow and transport

Organic transport in saturated systems

Multi-phase flow and transport of organics (gasoline)

Multi-phase explosives, fuels and solvents process

descriptions

Pesticide Transport

3-D non-uniform pesticide migration

PRA for nitrate contaminated groundwater

Non-point source pesticide transport

Non-point source nitrogen transport

2-D nutrient and pesticide transport

Non-point source pollutants in riparian systems

Pesticide transport in an agricultural watershed

Pesticide transport after irrigation

Water and dissolved salts

Comparison of alternative pesticide transport models

Develop soil classification system for pesticide

application

Pesticide and toxic organic transport

Solute Transport

Heavy metal transport - $\mathrm{Cr}, \mathrm{Cu}, \mathrm{Zn}$ (Otis Air Force Base)

Compilation, application, and evaluation of flow and
Performing

Institution

UNC

RSKERL

U.Texas EPA

U. Vermont EPA

Rice U. EPA

Princeton NSF

U. Alaska NSF

PNL DOE

Clarkson U. NSF

Auburn USDA

Colorado St USDA

VPI

USDA

Colorado U. NSF

USGS USGS

USGS USGS

USGS USGS

WES DoD

Wisconsin USDA

Nebraska USDA

UC - Davis USDA

VPI USDA

ARS USDA

ARS USDA

ARS USDA

UC- Riverside USDA

UC- Riverside USDA

UC - Berkeley USDA

Oklahoma St USDA

UC-Davis USDA

RSKERL EPA 
Title

transport models

Mercury transport

Inverse Problem - determine plume history

Transport in unstable wetting fronts

Transport in response to random fluctuations in rain fall

Coupled flow and solute transport in 2-D

3-D unsaturated/saturated flow and transport

Coupled flow and reactive transport

Fractal mathematics approach to flow and transport

3-D solute transport for spatially variable flow properties

Groundwater flow and transport model validation

Metal ion sorption models

Flow in dual porosity systems

Anomalous diffusion in random velocity fields

Stochastic

Water and solute

Water, solute, and vapor

Macro-dispersion, 3-D, sorption

Solute transport: Application to Melton Watershed

3-D solute transport

Stochastic modeling for network design

3-D fracture flow and solute transport

Field-scale demonstration of stochastic flow modeling

Water and solute transport

Solute transport with kinetic absorption

Sewage Plume - application at Otis Air Force Base

Solute transport

Stochastic hydraulic conductivity models
Performing

Institution

CO Mines

U. Nevada

UC- Riverside

NMIMT

U Cincinnati

USGS

USGS

USGS

N. Dakota St.

UC-Riverside

PNL

U. Maine

Wayne State

NYU

UNC

UC-Riverside

$\mathrm{U} . \mathrm{Az}$

ORNL

UC- Berkeley

Stanford

USGS

MIT

MIT

UC-Riverside

USGS

USGS

NMIMT

U. Arkansas

U. IL

ARS

PNL

DOE

Develop molecular scale models to support transport
Develole Chemical Modeling parameter choice

\section{Numerical Techniques}


Improved finite difference schemes for multi-phase flow and

Duke

NSF

transport

Improved finite difference methods

Grand challenge: groundwater modeling initiative

U. Washington

DOE

Moving front problems on parallel processors

(1)

DOE

Moving boundary problems

Fluent, Inc.

NSF

Algorithms for reactive flow and transport on parallel

U. Washington

NSF

processors

U. Vermont

NSF

\section{Optimal Data Collection}

Statistical approaches to Hydraulic Conductivity Data

Sampling strategies for statistical parameter estimation

Statistical design to minimize data collection

Real time parameter estimates for conductivity

Application of neural networks for site characterization

Geophysical data fusion

NMIMT

UCLA

USGS

Purdue

SAIC

Coleman

Research

LLNL

USGS

USGS

Oregon State

U. AZ

USGS

ARS

RSKERL

INEL

WES

BYU

Duke
DOE

NSF

USGS

DOE

DOE

DOE.

DOE

USGS

USGS

USDA

USDA

USGS

USDA

EPA

DOE

DoD

DoD

NSF 
Notes

(1) Groundwater modeling initiative is a multi-facility program including researchers from Rice, Texas A\&M, Stony Brook University, Brookhaven National Laboratory, Oak Ridge National Laboratory, and Savannah River Laboratory 



\section{Appendix $B$}

\section{Primary DOE and EPA Fate and Transport Modeling R\&D Programs}

This Appendix contains a list of programs supported by the DOE and the EPA. A brief abstract of each program is given along with the funding agency, and when the information was available, the level of funding and program duration. General descriptions of the EPA's R.S. Kerr groundwater modeling program, the EPA's ecological risk assessment program, and DOE's grand challenge in groundwater model development program are also provided.

Project:

Funding Agency:

Contact:
Containment of Contaminants through Physical Barriers Formed from Viscous Liquids Emplaced under Controlled Viscosity Conditions DOE - (ISRIP)

\section{Project Description:}

This project will identify and characterize promising materials and evaluate their containment potential by means of laboratory pilot-scale experiments, field testing and demonstration. The general purpose TOUGH2 model is being modified to simulate barrier fluid behavior and to design experiments.

Project:

Funding Agency:

Contact:
Modeling Strategies for Enhancing In-Situ Bioremediation DOE (ISRIP); EPA

Peter Kitanidis, Stanford University (415) 723-8321

\section{Project Description:}

This program will develop and apply mathematical models of subsurface flow of halogenated aliphatic compounds to develop conceptual designs for enhancing in situ bioremediation. The work will be focused on the Hanford and Rocky Flats sites. Investigation of the hydrodynamics of air sparging, development of the biofilm, and methods to avoid pore plugging will be made. 
Project:

Funding Agency:

Contact:
Optimal Remediation Design: Methodology and User-Friendly Software for Contaminated Aquifers DOE (ISRIP)

David Rice, LLNL, (510) 423-5059

\section{Project Description:}

This project focuses on the development of a methodology and associated tools for the management and optimization of remediation processes in contaminated groundwater in both unsaturated and saturated systems. Specific tasks include the development of a threedimensional groundwater simulators coupled with optimization based on hydrodynamic and solute transport constraints. Graphical interfaces will be developed for a variety of computers.

\section{Project:}

\section{Funding Agency:}

Contact:
Electrokinetic Removal of Heavy Metals and Mixed Wastes from Partially and Fully Saturated Soils DOE (ISRIP) Ronald Probstein, MIT (617) 253-2240

\section{Project Description:}

The objective of this task is to develop a mathematical model that can be used to determine the optimum operating conditions for electrokinetic decontamination of specific waste sites. A theoretical and experimental investigation will be conducted to provide the information required to refine a numerical model of the electrokinetic remediation process.

\section{Project:}

Duration:

Funding Agency:

Contact:
A Prototype Decision Support System to Select Cover Barrier Systems

FY' 93 - FY' 95

DOE - MWID

T. E. Haknoson, LANL, (505) 665-5281

\section{Project Description:}

A decision support system for selection of appropriate cover barrier technology is being developed to run on a PC-based system. The model will incorporate site-specific data from the Hill Air Force Base in Utah and will be used to select the appropriate landfill cover practice. Site monitoring data will be used to verify the predictions from the simulation model. 
Project:

Duration:

Funding Agency:

Contact:
Effects of Site Capping on Contaminant Transport

FY 92 - FY 94

DOE - MWID

Carol Stein, SNL (505) 844-5576

Project Description:

The focus of this study is an evaluation of the effects of an impermeable landfill cap on fluid migration in the unsaturated zone immediately beneath the cap. The project will develop a two-dimensional numerical modeling capability for coupled heat, liquid, and vapor transport.

Project:

Duration:

Funding Agency:

Contact:
Environmental Decision Support System

$1994-1996$

DOE- MWID, EPA, NRC

Bob Knowlton, SNL

\section{Project Description:}

The objective of this work is to provide site owners and operators a computer based data management/graphical display tool and a geostatistical tool known as the EDSS to support borehole and other sample optimization strategies based on risk assessment methodologies.

Project:

Funding Agency:

Contact:
Bacterial Transport

DOE Subsurface Sciences

J.F. McCarthy, ORNL

\section{Project Description:}

The goal of this program is to understand and predict the transport of bacteria in subsurface systems by focusing on microbial properties that affect their interaction with chemical and physical heterogeneities in natural subsurface systems. The secondary goal of the program is to use this knowledge to improve bioremediation.

Project:

Funding Agency:

Contact:
Intermediate-Scale Investigations of Interactive Subsurface Processes

DOE Subsurface Sciences

E.M. Murphy, PNL

Project Description:

A combination of lab-scale experimental and modeling work to understand the role of heterogeneities on subsurface transport of microbes. 
Project:

Funding Agency:

Contact:
Investigation of Three-Phase Transport in One- and TwoDimensional Bedded Porous Media

DOE Subsurface Sciences

J.S. Selker, Oregon State University

\section{Project Description:}

This research will quantify the physical properties that control the movement of NAPLs across bedding interfaces of fine over coarse sediments above the saturated zone. A numerical model will be adapted to predict three-phase flow in bedded vadose settings and will be validated using the results of one- and two-dimensional laboratory experiments.

\section{Project:}

Funding Agency:

Contact:
Mathematical and Geological Approaches to Minimizing the Data Requirements for Statistical Analysis of Hydraulic Conductivity Distributions

DOE Subsurface Sciences

F.M. Phillips, New Mexico Institute of Mining and Technology

\section{Project Description:}

This objective of this program is to develop techniques to obtain the statistical parameters needed to describe hydraulic conductivity. The program will examine depositional processes and correlate this with conductivity.

Project:

Funding Agency:

Contact:
Application of Particle Method to Multi-component Geochemical Reactive Transport Problems

DOE Subsurface Sciences

A.F.B. Tompson

\section{Project Description:}

The objectives of this task are to develop, extend, apply, and integrate, as necessary, a highly resolved model of miscible contaminant migration and transformation phenomena within a three-dimensional, nonuniform subsurface porous formation.

\section{Project:}

Funding Agency:

Contact:
Modeling of Coupled Processes in Subsurface Transport of Reactive Contaminants

DOE Subsurface Sciences

A.J. Valocchi, University of Illinois

\section{Project Description:}

The general objective of this program is to develop and apply a multidimensional transport model for multiple components undergoing kinetically or equilibrium-controlled chemical and biological reactions. 
Project:

Funding Agency:

Contact:
Analysis of Modeling of Mobilization and Transport of Natural Organic Matter in Heterogeneous Geologic Systems

DOE Subsurface Science Program

T.C.J. Yeh, University of Arizona

\section{Project Description:}

The objectives of this work are to develop a computationally feasible algorithm for simulation of colloid transport in multidimensional heterogeneous porous media under variably saturated conditions, to investigate the potential of conditional concepts for designing sampling procedures that improve our prediction of colloid migration in a subsurface environment, and to apply numerical models and conceptual approaches to real field sites to address realistic issues.

Project:

Field Scale Validation and Development of a Three-Dimensional Fluid Flow and Multi-species Hydrogeochemical Transport Model

Funding Agency: DOE Subsurface Sciences

Contact:

G.T. Yeh, Penn State

\section{Project Description:}

The objectives of this research are to spatially characterize the key subsurface chemical and physical heterogeneity properties controlling contaminant mobility at a field facility on the Melton Branch Watershed at ORNL, to develop an efficient and accurate numerical algorithm for the simulation of multi-component transport, to develop a true three-dimensional fluid flow and hydrogeochemical transport model, and to validate the model with measured fluxes and chemical distributions in the Melton Branch Watershed.

Project:

Funding Agency:

Contact:
Subsurface Chemistry of Organic-Radionuclide Mixtures DOE Subsurface Sciences John Zachara, PNL

\section{Project Description:}

The program involves (1) interaction experiments of complex radionuclides with suspensions of natural material to establish adsorption magnitude, transformation kinetics, and reaction stoichiometry; (2) developing multi-reaction surface complexation models consistent with experiment; and (3) collaborative experiments with others to validate the proposed reaction mechanisms. 
Project:

Funding Agency:

Contact:
Real-Time Adaptive Parameter Estimation for Multi-scale Heterogeneous Systems DOE Subsurface Sciences

J.H. Cushman, Purdue

Project Description:

The objective of this program is to (1) develop a multi-scale adaptive estimators for the conductivity field in a heterogeneous environment using conservative tracer and head data;

(2) develop constitutive models for contaminant transport in multi-scale heterogeneous subsurface environments and find conditions where scaling laws hold; and (3) complete molecular-scale modeling efforts for micro-porous systems.

$\begin{array}{ll}\text { Project: } & \text { Multi-phase Fluid Flow } \\ \text { Funding Agency: } & \text { DOE Subsurface Sciences } \\ \text { Contact: } & \text { K.F. Hayes, Michigan }\end{array}$

Project Description:

The objective of this research is to understand how changes in interfacial properties affect multi-phase flow in contaminated aquifers. Sorption of solutes alters the interfacial properties of the system, such as the liquid-liquid interfacial tension and contact angle. A quantitative relationship between the degree of sorption and the multi-phase flow properties such as capillary pressure-saturation relationships is being developed. The quantitative relationship depends on the $\mathrm{pH}$, organic carbon content, and the presence of co-contaminants such as metal ions or organic acids.

Project: Subsurface Organic Fluid Flow

Funding Agency: DOE Subsurface Sciences

Contact: R.J. Lenhard, PNL

\section{Project Description:}

The objective if this project is to improve the knowledge of how NAPLs move and distribute through subsurface porous media. A secondary goal is to develop modeling strategies for predicting NAPL behavior under field conditions. The approach used to reach these objectives is to analyze intermediate-scale experiments of the effects of pore-scale processes on NAPL flow and retention. The main areas of interest are the effects of microbial growth on NAPL flow and transport and the relationships between multi-phase relative permeabilities, fluid contents, and fluid pressures as a function of porous media and NAPL type. 
Project:

Funding Agency:

Contact:

Percolation Modeling of Microbial Transport and Dynamics DOE Subsurface Sciences

C.S. Loehle, ANL

Project Description:

The objective of this work is to develop a modeling framework and specific models and analyses that incorporate microbial dynamics and behaviors into hydrologic transport process models.

Project:

Duration:

Funding Agency:

Contact:
International Environmental Assessment

FY 1992 - FY 1999

DOE - CMST-IP

D.J. Bradley, PNL (509) 372-4161

Project Description:

PNL is developing three-dimensional numerical models of the hydrogeology and contaminant migration in the West Siberian Basin. The model is being calibrated to the site through the use of field data.

Project:

Duration:

Funding Agency:

Contact:
Contaminant Transport Studies of Russian Sites

FY 1993 - FY 1996

DOE - CMST-IP

Chin-Fu Tsang, LBL, (510) 486-5782

\section{Project Description:}

This program will evaluate site characterization and monitoring data from Russian contamination sites, conduct field evaluation of these sites, and develop approaches for site evaluation and remediation. Data from this study can be used to validate other transport models.

Project:

Funding Agency:

Contact:

\section{Project Description:}

The Groundwater Modeling System (GMS) is a comprehensive graphical user environment for numerical modeling. GMS is intended to be used for groundwater modeling applications, but the interface has been written in a general fashion so that it can be used as a platform for any type of two- or three-dimensional numerical modeling. A large number of visualization tools have been provided in GMS.
GMS - Groundwater Modeling System

DoD, DOE, EPA

Brigham Young University Computer Graphics Laboratory (801)378-2812 
Project:

Funding Agency:

Contact:
Exposure Models Library and Integrated Model Evaluation System (IMES)

EPA - Office of Health and Environmental Assessment

Richard Wollentiwicz, EPA (202)

\section{Project Description:}

The IMES is an interactive expert system that selects appropriate groundwater fate and transport models from the Exposure Models Library. Model selection occurs as a result of the user specifying requirements for the code (e.g., three-dimensional, flow and transport, organics, etc.)

Project:

Funding Agency:

Contact:

Project Description:

Project:

Funding Agency:

Contact:

Project Description:

Project:

Funding Agency:

Contact:
Optimization of Sampling Strategies for Containment and Risk Management DOE - MWID

R. Johnson, ANL, (708) 972-2203
Engineering Simulator

DOE - MWID

K. Roberson, PNL (509) 376-3514

\section{Project Description:}

The objective of this program is to develop an inexpensive analytical tool that can interpolate waste concentrations and flow contours between widely spaced boreholes. The computer model will rely on neural network algorithms.

Project:

Duration:

Funding Agency:

Contact:
[Not available]

Application of Neural Networks to Site Characterization DOE - Innovation Investment Area Ali Dabiri, SAIC (619) 458-5284

\section{Project Description:}

The purpose of this program is to develop a software package that will fuse geophysical, hydrological and chemical data derived from multiple sensor technologies to characterize hazardous waste sites. 
Project:

Microbial Transport in Porous Media

Funding Agency:

DOE -- Innovation Investment Area and EPA Hazardous Substances Research Center (HSRC)

Contact:

A.B. Cunningham, Montana State University, (406) 994-4770

Project Description:

The goal of this project is to develop a phenomenological basis for the design and operation of systems for injection/infiltration of microorganisms to enhance contaminant biotransformation in soil and groundwater. 


\section{R.S. KERR ENVIRONMENTAL RESEARCH LABORATORY}

The following list of projects are supported through the R.S. Kerr Laboratory.

Project:

Duration:

Funding Agency:

Contact:
Three-Dimensional Modeling of Subsurface Flow, and Fate and Transport of Microbes and Chemicals $1991-1994$

EPA

George Yeh, Penn State University (814) 863-2931

\section{Project Description:}

Develop a 3-dimensional numerical model of contaminant fate and chemically reactive transport in unsaturated/saturated flow fields.

Project:

Duration:

Funding Agency:

Contact:
Validation of the Approximate Multi-phase Flow Models $1991-1994$

EPA

James Weaver, RSKERL, (405) 436 - 8545

\section{Project Description:}

The object of this project is to test the Kinematic Oily Pollutant Transport (KOPT) portion of the Hydrocarbon Spill Simulation Model (HSSM) by comparison with laboratory data.

Project:

Duration:

Funding Agency:

Contact:
Heavy Metal Transport in a Sand and Gravel Aquifer with Variable Chemical Conditions

$1992-1995$

EPA

James Davis

\section{Project Description:}

Field studies at the Otis Air Force Base. Data will be used to improve reactive transport modeling for chromium (VI), copper, and zinc.

Project:

Duration:

Funding Agency:

Contact:

\section{Project Description:}

The objectives of this project are to enhance the existing knowledge of groundwater models and their utility and performance, develop guidance in applying quality assurance in model development, and address other scientific issues related to the use of groundwater models. 
Project:

Duration:

Funding Agency:

Contact:
Development of a Data Evaluation/Decision Support System for Bioremediation of Subsurface Contamination

$1993-1996$

EPA

P. Bedient, Rice University, (713) 527-4953

\section{Project Description:}

Develop a computer based system which will accept both "hard" and "soft" data in threespatial dimensions plus time and allow interpretation into a conceptual model(s) of the hydrogeologic environment. Visualization of the models will be supplied. A data evaluation/decision support system for bioremediation of subsurface contamination will be developed.

\section{Project:}

Duration:

Funding_Agency:

Contact:
Decision Support System for Evaluating Remediation Performance with Interactive Pump-and-Treat Simulator $1992-1994$ EPA

P. Bedient, Rice University, (713)527-4953

\section{Project Description:}

The goal of this project is to develop a PC-based decision support system for evaluating the effectiveness of pump-and-treat networks at Superfund sites.

Project:

Duration:

Funding Agency:

Contact:
Modeling and Design of Bioremediation Systems for a JP-4 Jet Fuel Spill at Elgin AFB, Florida 1992 - 1995

EPA

Herb Ward, (713) Rice University, 527-4086

\section{Project Description:}

The object of this project is to use site characterization and modeling to provide design for bioremediation systems to be used for the field demonstration project on nitrate-based bioremediation. 


\section{Project:}

Duration:

Funding Agency:

Contact:
Site Characterization of Groundwater Flow and Transport in Fractured Rock Systems for Improvement of Pump-and-Treat Remediation

$1991-1994$

EPA

Kenzi Karasaki, LBL, (415) 486-4289

\section{Project Description:}

The project is designed to investigate the effects of fractured network complexity on the efficiency of the pump-and-treat methods of aquifer remediation. Model results will be compared to geophysical and hydrological tests.

Project:

Duration:

Funding Agency:

Contact:
Three-Dimensional NAPL Fate and Transport Model $1993-1996$

EPA

Gary Pope, University of Texas, (512) 471-3235

\section{Project Description:}

The objective of this project is to develop a three-dimensional model that describes subsurface contaminant transport and transformation in a groundwater aquifer with spatially and temporally varying conditions. A computer code with a user's manual will be developed and a workshop will be hosted for model users.

\section{Project:}

Duration:

Funding Agency:

Contact:
Development of Data Evaluation/Decision Support System for Bioremediation of Subsurface Contamination $1993-1996$

EPA

Dennis McLaughlin, MIT, (617) 253-7176

\section{Project Description:}

The objective of this project is to develop computerized interpretation capabilities for both soft (qualitative) and hard (quantitative) field data of hydrogeologic environments. The computer-aided conceptual model is to integrate knowledge of physical transport processes in terms of a flow and transport model with statistical techniques and geologic formation processes. Output includes 3-D image of hydrogeologic environment, spatial and temporal distribution of contamination, and where to obtain samples to optimally refine the conceptual model. 


\section{Project:}

Duration:

Funding Agency:

Contact:

Project Description:

The objective of this project is to develop mathematical modeling of the processes involved in the movement of mixtures of non-aqueous phase liquids through the vadose zone into the aquifer.

Project:

Duration:

Funding Agency:

Contact:
Three-Dimensional Multi-phase Flow and Contaminant

Transport Mathematical Model

$1992-1995$

EPA

George Pinder, University of Vermont, (802) 656-3390

Project Description:

The objective of this project is to extend the Hydrocarbon Spill Screening Model to include additional processes and geologic settings. Five areas are proposed for extension of the model: heterogeneous media in the vadose zone, volatilization of the chemical, flow of DNAPLs, biodegradation in the saturated zone, and flow of NAPLs in the capillary fringe. 


\section{SUMMARY OF EPA RESEARCH AT THE ENVIRONMENTAL RESEARCH LABORATORY, ATHENS, GA.}

The following is a list of projects at the Environmental Research Laboratory, Athens, GA:

Project:

Funding:
Ecology/Transport/Fate/Field Validation

$\$ 3,370,300$

\section{Project Description:}

Research will concentrate on the development, refinement, and validation of techniques and models to measure and predict pesticide transport, degradation, exposure, effects, and fate in the environment. Laboratory and field studies will be conducted to substantiate the applicability of methods and mathematical models and to determine if results are valid and reflect environmental responses under natural conditions. Data from these studies will be used to assess pesticide hazards to surrogate species, populations, and communities representative of aquatic (i.e., estuarine) and terrestrial habitats.

These investigations will include analysis of abiotic influences on study results and on various chemical and physical factors and processes. Sorption, leaching, and bioaccumulation will be evaluated. Groundwater contamination and associated processes will be explored and remedial actions sought. Information systems will be developed and used to help implement management strategies to prevent pesticide contamination of groundwater. Predictive techniques for exposure assessment technology will be improved with studies on pesticide sorption kinetics, transformations, structure reactivity correlations and mechanisms of degradation. Terrestrial ecotoxicology studies will include development of data and methods to assess and predict stress impacts on wildlife (e.g., bird) populations including comparability between lab and field tests. Information and data including assessments and predictive tools, evaluations of assessment criteria, models and user manuals, workshops and reviews are applied to support the Agency's regulatory actions.

Project:

Funding:
Ecology: Ecotoxicity and Risk Assessment FY 1992 $\$ 1,995,400$

\section{Project Description:}

To register or re-register pesticides, it is necessary to develop a focused risk assessment process for integrating hazard and exposure assessments to estimate the probability of risk to important non-human populations. This facet of the research program develops environmental risk assessment methodology by combining impact data using existing or new models to express risk as a probability with estimates of the associated uncertainty.

New endpoint responses will be studied encompassing ecosystem structures and function. Selected wildlife and microbial populations will be used to reflect population changes and other changes that influence risk evaluations. Other parameters that affect model integrity will be studied (e.g., species susceptibility, chemical routes of exposure, and uptake and 
residues). Modeling will be supported through data integration and model calibration, and validation will be supported through field studies that include all media. A pesticide ranking index and registry system is being developed as a tool for assessing selected aquatic systems.

Project:

Duration:

Funding:

Performing Org.:

Sponsoring Org.:

Contact:

Add'l Contacts:
Ecology: Ecotoxicity and Risk Assessment (FY 1992) 911001 TO 920930 $\$ 1,501,700$

Environmental Research Laboratory/ATH, Athens, Georgia 30613

Office of Research and Development, $401 \mathrm{M}$ Street, SW, Washington, District of Columbia 20460

Russo, R.

Murphy, T.; Veith, G.; Menzer, R., Jaworski, N. (project monitor)

\section{Project Description:}

Environmental risk assessment studies on the linkage of environmental exposure and ecotoxicology hazard assessment techniques and development of methods to evaluate risks continues. The goal is to predict toxic risk to varied ecosystems and components within acceptable limits of uncertainty.

The ecotoxicology studies include the movement, transformation and ultimate disposition of toxic substances in all environmental media as a critical component of risk assessment. How plants and animals or ecosystems and biological interactions are affected by toxic substances are also the subjects of this research effort. Research goals include the identification of important endpoints and development of mathematical modeling techniques (population, transport) to integrate data and depict risk. Input data will include such resuits as lab-to-field comparative responses, measurements of ecosystem resistance and resilience, recovery, population changes (mortality, feeding behavior), biota uptake, and susceptibility.

Techniques such as quotient-based approaches at various scales of system complexity and causative factors affecting variations in toxicity data (taxonomic considerations) and modeling results will be studied. The validated predictive tools and the results will be used in regulatory decision-making and as a guide to formulating regulatory criteria and standards.

Project:

Duration:

Funding:

Performing Org.:

Sponsoring Org.:

Contact:

Add'l Contacts:
Ecology: Transport/Fate/Field Validation (FY 1992)

FY-1992

$\$ 2,424,800$

Environmental Research Laboratory/ATH

Athens, Georgia 30613

Office of Research and Development, $401 \mathrm{M}$ Street, SW, Washington, District of Columbia 20460

Russo, R.

Menzer, R.; Murphy,T. 


\section{Project Description:}

This research encompasses the determination of the effects, movement, transformation, and ultimate disposition of toxic substances and their degradation products that inadvertently enter into all environmental media. This program provides information on how plants and animals and larger ecosystems are affected by exposure to toxic substances caused by accidents in commerce and industry. Specific activities include developing and validating techniques for assessing hazards and exposure, and estimating the fate of existing chemicals through lab, microcosm, or field studies. Information developed in the above studies provides data necessary for hazard and exposure assessments and for designing mathematical models of chemical transport, transformation, and fate including biodegradation.

Research addresses such problem areas as: inter-media transfer, characteristics of chemicals (e.g., chemical kinetics/hydrolysis and microbial rate constants) and the processes of the receiving environment; comparative toxicological responses; system level effects (e.g., community alterations); effects of toxicants on animal and plant development and applied chemical structure-activity techniques, methods for measuring ecosystem recovery and abiotic transformation. Research results help the agency to determine potential adverse impacts of toxicants and to help formulate preventative or remedial actions. 


\title{
SUMMARY OF EPA RESEARCH IN ROBERT S. KERR, ENVIRONMENTAL RESEARCH LABORATORY, ADA, OK.
}

\author{
FUNDING for FY-1992: $\quad \$ 6,592,200$
}

\section{Project Description:}

Groundwater is a major source of drinking water for the nation. This research program provides both technical information and improved methods for predicting contamination movement and transformation. The research focuses on methods development for studies of subsurface transport and fate processes such as biological transformation, oxidation-reduction, hydrolysis, and ion exchange. Facilitated transport research will address complex mixtures processes such as multiphase transport and solvent composition effects on sorption.

Field evaluation of techniques for determining the mechanical integrity and adequacy of construction of injection wells will occur. Methods will be developed for delineating wellhead protection areas, incorporating multiple sources of pollution into wellhead protection models, and for performing risk assessments in wellhead protection areas.

A new program entitled Midwest Agrichemical Surface/Subsurface Transport and Effects Research (MASTER) will be implemented. This is a cooperative effort with the USDA and USGS. The research will evaluate how agricultural management practices affect our ecological resources with a goal towards optimizing the ecological health of agricultural watersheds. 


\section{SUMMARY OF DEPARTMENT OF AGRICULTURE (AGRICULTURAL RESEARCH SERVICE - ARS) PROGRAM}

Research areas of emphasis for water quality are as follows:

1) Determine fate and transport of nutrients and pesticides in the soil and minimize invasion into groundwater;

2) Improve management of riparian areas adjacent to streams and ponds;

3) Develop management systems using cover crops and rotations to eliminate contamination of water supplies; and

4) Assess mutagenicity of natural and manufactured contaminants. 


\section{DOE GRAND CHALLENGE IN GROUNDWATER TRANSPORT IN ENVIRONMENTAL MODELING AND REMEDIATION}

\section{Project Description:}

This proposal is directed at the Grand Challenge in Groundwater Transport in Environmental Modeling and Remediation, a part of the Partnership in Computational Science.

Two-dimensional and 3-D saturated and unsaturated flow codes will be developed.

Extensions of these codes to more complex geometries will involve the development of effective data structures, solution algorithms, and preconditioners. There will be parallelization efforts for the flow codes. Researchers at Texas A\&M University will then participate in the development and testing of combined-flow and transport codes working closely with researchers from Rice University. Flow and transport codes will be prepared for interface with parameter estimation techniques. Numerical treatment and analysis will be developed for prototype problems for the determination of nonlinear coefficients in the presence of heterogeneities.

Data acquisition requirements for parameter estimation at Oak Ridge National Laboratory (ORNL) field sites will be determined. Imaging technology needed to obtain important software local reservoir properties from field cores will be developed. Local grid, refinement techniques, and domain decomposition methods that will be important computational techniques for treating the localized phenomena in the simulations of containment transport will continue to be developed. Researchers from Brookhaven National Laboratory (BNL) will assist in the development and utilization of higher-level language constructs for effective parallelization of the codes. Development of scientific visualization tools will continue. The postprocessing visualization effort will provide software tools that implement some of today's state-of-the-art 3-D visualization techniques. The software tools will include isosurface, slicer-dicer, simplistic vector visualization techniques with implementations on certain generalized 3-D geometries. These software tools will be made available on several vendor's workstations using $\mathrm{X}, \mathrm{gl}$, and NeWS capabilities. 


\section{Appendix $C$}

\section{Federal Research in Progress Database (FEDRIP)}

The Federal Research in Progress (FEDRIP) Database was used as a major source for determining current efforts in fate and transport modeling. The database can be accessed through the DIALOG information services system. The FEDRIP database provides access to information about ongoing federally-funded research projects in the fields of physical sciences, engineering, and life sciences; research information is provided to NTIS by the sponsoring U.S. government agencies. All records in the database include title, principal investigator, performing organization, and sponsoring organization. Most records. also include a description of the research, although the exact record content varies according to the sponsoring agency.

This database contained over 300 programs involving modeling contaminant fate and transport. Approximately half of these were primarily modeling programs, while the other half were experimental programs that used modeling to interpret experimental data. The entire listing was over 300 pages. The file has been subdivided into two categories depending on the emphasis of the program (modeling or experimental). An electronic version of the files is available through contacting one of the authors of this report. This file contains all projects listed in Appendix A.

Research summaries are contributed by the USDA, DOE, OSHA, NIH, and USGS, as well as the National Aeronautics and Space Administration (NASA), the National Institute of Standards and Technology (NIST), the Transportation Research Board, and the Veterans Administration. A sample record from the database follows.

IDENTIFYING NO.: 9218803; 9218803 AGENCY CODE: NSF

A Pore-Scale Computational Model for the Simulation of Mass Transfer From Nonaqueous Phase Liquids

PRINCIPAL INVESTIGATOR: Celia, Michael A Dr.

PERFORMING ORG.: Princeton University, Department Civil Engineering, Princeton, NJ 08544

PROJECT MONITOR: L. Douglas James 
SPONSORING ORG.: National Science Foundation, DIVISION OF EARTH SCIENCES, Washington, D.C., 20550

DATES: 930301 TO 950831

FY : 95 FUNDS: $\$ 275,000$

TYPE OF AWARD: Continuing Grant

SUMMARY: This study will provide a physically-based description of the mass transfer process in multi-fluid porous media. By developing a pore-scale miscible transport model and coupling it with existing pore-scale models for fluid-fluid displacement, a complete and self-consistent mathematical description of capillary displacement, fluid motion, interphase mass transfer, and miscible contaminant transport will be obtained. With this model, mass transfer coefficients will be predicted as functions of interfacial areas, which will be directly related to fluid saturations. Comparison of model results to a number of reported laboratory experiments involving non-aqueous phase liquid (NAPL) dissolution will be used to validate the model. Correlations between predicted mass transfer coefficients and capillary pressure-saturation-relative permeability relations will be explored. The model will be used to investigate the functional dependence between dispersivities and fluid saturations, including examination of possible hysteresis. Finally, the influence of material heterogeneity will be explored, with an emphasis on determination of effective mass transfer coefficients and macro-dispersivities. The practical utility of the results will be demonstrated by coupling the continuum-scale transport properties predicted by the pore-scale models to more traditional continuum-scale multi-phase simulators.

DESCRIPTORS: Geological Sciences 
